\title{
The Survival of Motor Neuron (SMN) Protein Interacts with the mRNA-Binding Protein HuD and Regulates Localization of Poly(A) mRNA in Primary Motor Neuron Axons
}

\author{
Claudia Fallini, ${ }^{1 *}$ Honglai Zhang, ${ }^{3 *}$ Yuehang Su, ${ }^{1}$ Vincenzo Silani, ${ }^{4}$ Robert H. Singer,${ }^{3}$ Wilfried Rossoll, ${ }^{1}$ \\ and Gary J. Bassell ${ }^{1,2}$ \\ ${ }^{1}$ Department of Cell Biology and 2Department of Neurology and Center for Neurodegenerative Diseases, Emory University School of Medicine, Atlanta, \\ Georgia 30322, ${ }^{3}$ Department of Anatomy and Structural Biology, Albert Einstein College of Medicine, Bronx, New York 10461, and ${ }^{4}$ Dipartimento di \\ Neuroscienze, Università degli Studi di Milano, Istituto di Ricovero e Cura a Carattere Scientifico Istituto Auxologico Italiano, 20149 Milano, Italy
}

Spinal muscular atrophy (SMA) results from reduced levels of the survival of motor neuron (SMN) protein, which has a well characterized function in spliceosomal small nuclear ribonucleoprotein assembly. Currently, it is not understood how deficiency of a housekeeping protein leads to the selective degeneration of spinal cord motor neurons. Numerous studies have shown that SMN is present in neuronal processes and has many interaction partners, including mRNA-binding proteins, suggesting a potential noncanonical role in axonal mRNA metabolism. In this study, we have established a novel technological approach using bimolecular fluorescence complementation (BiFC) and quantitative image analysis to characterize SMN-protein interactions in primary motor neurons. Consistent with biochemical studies on the SMN complex, BiFC analysis revealed that SMN dimerizes and interacts with Gemin2 in nuclear gems and axonal granules. In addition, using pull down assays, immunofluorescence, cell transfection, and BiFC, we characterized a novel interaction between SMN and the neuronal mRNA-binding protein $\mathrm{HuD}$, which was dependent on the Tudor domain of SMN. A missense mutation in the SMN Tudor domain, which is known to cause SMA, impaired the interaction with HuD, but did not affect SMN axonal localization or selfassociation. Furthermore, time-lapse microscopy revealed SMN cotransport with HuD in live motor neurons. Importantly, SMN knockdown in primary motor neurons resulted in a specific reduction of both $\mathrm{HuD}$ protein and poly $(\mathrm{A})$ mRNA levels in the axonal compartment. These findings reveal a noncanonical role for SMN whereby its interaction with mRNA-binding proteins may facilitate the localization of associated poly(A) mRNAs into axons.

\section{Introduction}

Spinal muscular atrophy (SMA) is characterized by the specific degeneration of spinal cord motor neurons caused by a reduction in the ubiquitously expressed survival of motor neuron (SMN) protein (Burghes and Beattie, 2009). SMN localizes to both the cytoplasm and nuclear bodies called gems and, together with Gemin2-8 and Unrip forms a multimeric complex (Meister et al., 2002; Kolb et al., 2007) that facilitates the assembly of Sm/LSm proteins on U snRNAs into the spliceosomal small nuclear ribonucleoprotein (snRNP) core (Battle et al., 2006; Chari et al.,

Received June 11, 2010; revised Dec. 8, 2010; accepted Jan. 5, 2011.

This work was supported by an SMA Europe fellowship to C.F.; National Institutes of Health (NIH) Grant HD055835, the Spinal Muscular Atrophy Foundation, and the Weisman Family Foundation, to G.J.B.; and NIH Grant NS066030 to W.R. The Neuronal Imaging Core is supported by Emory Neuroscience-National Institute of Neurological Disorders and Stroke Core Facilities Grant P30NS055077. We thank Dr. Atsushi Miyawaki, Dr. Roger Tsien, Dr. Angus Lamond, and Dr. Nora Perrone-Bizzozero for providing plasmids, and Dr. Utz Fischer for Gemin2 antibody. We are indebted to Dr. Georg Haase and Dr. Thierry Bordet for help with establishing the motor neuron isolation protocol. We thank Lei Xing for sharing Venus yellow fluorescent protein BiFC vectors and subcloning plasmids. We also thank Lian Li and Andrew Swanson for excellent technical support.

*C.F. and H.Z. are co-first authors.

Correspondence should be addressed to either Dr. Gary J. Bassell or Dr. Wilfried Rossoll, Emory University School of Medicine, Department of Cell Biology, Whitehead Biomedical Research Bld. \#415, 615 Michael St., Atlanta, GA 30322. E-mail: gbassel@emory.edu or wrossol@emory.edu.

DOI:10.1523/JNEUROSCI.3631-10.2011

Copyright $\odot 2011$ the authors $\quad 0270-6474 / 11 / 313914-12 \$ 15.00 / 0$
2009). Despite the progress in understanding SMN housekeeping function, the reason for the unique vulnerability of motor neurons to low levels of SMN is still unknown.

mRNA transport and local translation are thought to be particularly relevant for highly polarized cells such as neurons (Holt and Bullock, 2009). Disruption and deregulation of mRNA splicing, transport, or local translation have been linked to various neurodegenerative diseases, including amyotrophic lateral sclerosis, distal SMA I and V, and distal hereditary neuropathies (Anthony and Gallo, 2010; Lemmens et al., 2010). A variety of mRNA-binding proteins such as hnRNP-R/Q, KSRP (KH-type splicing regulatory protein), and FMRP (fragile X mental retardation protein) have been shown to associate with SMN (Rossoll and Bassell, 2009), and motor neurons derived from a severe SMA mouse model show defective accumulation of $\beta$-actin mRNA at axon tips (Rossoll et al., 2003). Furthermore, SMNcontaining granules have been found to localize and be transported in processes and growth cones of motor neurons (Fallini et al., 2010) and forebrain neurons together with Gemin2 (Zhang et al., 2006). Although these observations suggest a link between SMN and the mRNA-transport machinery, whether SMN deficiency impairs general mRNA trafficking in motor neuron axons has never been demonstrated. Additionally, it is still unknown 
whether SMN, either alone or associated with components of the SMN complex, interacts with mRNA-binding proteins in individual granules, regulating their activity and axonal localization.

In this study, we have addressed a potential noncanonical function of SMN in axons by characterizing a novel interaction with the neuronal-specific mRNA-binding protein $\mathrm{HuD}$. $\mathrm{HuD}$, a member of the ELAV (embryonic lethal abnormal vision) family, binds to AU-rich elements in the $3^{\prime}$ - untranslated region ( $3^{\prime}$ UTR) of target mRNAs and controls their stability and translation (Aronov et al., 2001; Atlas et al., 2004; Smith et al., 2004; Tiruchinapalli et al., 2008). HuD has a well established role in neuronal development and plasticity (Perrone-Bizzozero and Bolognani, 2002), and HuD-deficient mice exhibit specific motor deficits, such as abnormal hindlimb reflex and poor rotarod performance (Akamatsu et al., 2005).

By using quantitative colocalization and bimolecular fluorescence complementation (BiFC), we show that SMN and $\mathrm{HuD}$ colocalize in actively transported axonal granules that are devoid of Sm proteins. The SMN-HuD interaction depended on the SMN Tudor domain and an SMA patient-derived missense mutation in this domain dramatically reduced the interaction. Importantly, low SMN levels impaired the localization of $\mathrm{HuD}$ and of poly(A)-positive mRNAs specifically in the axons of primary motor neurons, supporting a role for SMN in mRNA trafficking and suggesting possible mechanisms that may underlie axonal defects in SMA.

\section{Materials and Methods}

Primary motor neuron culture and transfection. Primary motor neurons from embryonic day 13.5 (E13.5) mouse embryos were isolated, cultured, and transfected by magnetofection as previously described (Fallini et al., 2010). Monomeric green fluorescent protein (mEGFP) or red fluorescent protein (mCherry) were fused to murine wild-type or mutant SMN, human Gemin2, and human HuD cDNAs. A flexible linker [(SGGG $\left.)_{3}\right]$ was inserted between the fusion partners to facilitate correct protein folding. GFP SmD1, mCherry cDNA, and hemagglutinin (HA)tagged Unrip constructs were kindly provided by Dr. Angus Lamond (Wellcome Trust Centre, London, UK) (Sleeman and Lamond, 1999), Dr. Roger Tsien (University of California, San Diego, La Jolla, CA) (Shaner et al., 2004), and Dr. Pran K. Datta (Vanderbilt University Medical Center, Nashville, TN) (Datta et al., 1998). The shRNA vectors (Open Biosystems) were used as described previously (Fallini et al., 2010).

Chick forebrain and rat hippocampal culture. Chick forebrain neurons were cultured as described previously (Zhang et al., 2003). Rat cortical neurons (E18), obtained from Gene Therapy System, were grown on poly-L-lysine $(1 \mathrm{mg} / \mathrm{ml})$-coated coverslips in N3 conditioned medium for $3 \mathrm{~d}$. Neuronal transfections were performed using DOTAP liposomal reagent (Roche) as described previously (Zhang et al., 2003).

Coimmunoprecipitation and Western blots. Total mouse (E12.5, E16, and postnatal day 20) and rat (E18) spinal cords were lysed in lysis buffer (50 mм Tris- $\mathrm{HCl}, 150 \mathrm{~mm} \mathrm{NaCl}, 2 \%$ Triton X-100, protease inhibitors). SMN immunoprecipitation (anti-SMN 2B1, Sigma) was performed using protein G-agarose beads (Roche) following the manufacturer's recommendations. Incubation with no antibody and mouse IgG (Sigma) were used as controls. Endogenous $\mathrm{SMN}$ and $\mathrm{HuD}$ proteins were detected using an SMN monoclonal antibody (1:2000, BD Biosciences) and a HuD polyclonal antibody (1:1000, Millipore).

HEK293 cells, cultured in DMEM containing 10\% FBS, were transfected with FLAG- and EGFP-tagged constructs using Lipofectamine 2000 (Invitrogen) or TurboFect (Fermentas) according to the manufacturer's recommendations. One day after transfection, cells were lysed ( 50 $\mathrm{mm}$ Tris- $\mathrm{HCl}, 150 \mathrm{~mm} \mathrm{NaCl}, 0.1 \% \mathrm{NP}-40$, and $0.1 \%$ sodium deoxycholate, $\mathrm{pH}$ 7.4) and the whole-cell extract was incubated with a rabbit anti-FLAG antibody (1:500, Sigma) and protein-A agarose beads (Roche) at $4^{\circ} \mathrm{C}$ overnight with rotation. After washing with a high-salt buffer (50 mm Tris- $\mathrm{HCl}, 300 \mathrm{~mm} \mathrm{NaCl}, 0.1 \% \mathrm{NP}-40)$, the agarose pellets were separated on a $4-12 \%$ SDS-PAGE gel for Western blot analysis. Monoclonal antibodies to FLAG (1:4000, Sigma) or EGFP (1:5000, BD Biosciences) were used for detection of FLAG- and EGFP-fusion proteins. For RNase treatment, protein extracts were incubated with or without $1 \mathrm{mg} / \mathrm{ml} \mathrm{RNase} \mathrm{A}$ for $1 \mathrm{~h}$ at $37^{\circ} \mathrm{C}$ before immunoprecipitation.

GST-binding assay. cDNAs of SMN or $\mathrm{HuD}$ were subcloned into pGEX-6p-1 vector and transformed into the BL21 Escherichia coli strain. Expression of GST fusion proteins was induced using IPTG (1 mM) for 3 h. Glutathione Sepharose beads (GE Healthcare) bound to GST-SMN or GST-HuD were washed (PBS, $500 \mathrm{~mm} \mathrm{NaCl}, 0.1 \%$ Triton X-100) and incubated with the protein extracts from rat brain tissues at $4^{\circ} \mathrm{C}$ overnight. As controls, GST tag and glutathione Sepharose beads alone were incubated with the protein extracts. After washing with TBS containing $500 \mathrm{~mm} \mathrm{NaCl}$, proteins from the bead pellets $(\mathrm{P})$ and supernatant $(\mathrm{S})$ were run on $4-12 \%$ gradient gels for Western blot analysis. Membranes were incubated with antibody to $\mathrm{HuD}$ (Millipore) or SMN (BD Biosciences).

Cell staining and imaging. Motor neurons were fixed for $15 \mathrm{~min}$ with $4 \%$ paraformaldehyde in PBS $24 \mathrm{~h}$ or $5 \mathrm{~d}$ after transfection, as indicated. Anti-SMN (1:500; BD Biosciences), monoclonal HuD (1:500; 16C12, Abcam), polyclonal HuD (1:500; Millipore), Gemin2 (1:1000; provided by Dr. Utz Fischer, University of Wuerzburg, Germany), glycyl-tRNA synthetase (GARS; 1:250; Epitomics), Unrip (1:500; BD Biosciences), and HA (1:1000; HA7, Sigma-Aldrich) antibodies were incubated overnight at $4^{\circ} \mathrm{C}$. Cy3-, Cy2- or Cy5-conjugated secondary antibodies (Jackson ImmunoResearch) were incubated for $1 \mathrm{~h}$ at room temperature. $Z$-series (5-10 sections, $0.2 \mu \mathrm{m}$ thickness) were acquired with an epifluorescence microscope ( $\mathrm{Ti}, \mathrm{Nikon}$ ) equipped with a cooled CCD camera (HQ2, Photometrics). Motor neuron axons were identified by morphology as the longest unbranched cell process.

Bimolecular fluorescence complementation. The N- and C-terminal fragments of Venus yellow fluorescent protein (VFP) (a kind gift from Dr. Atsushi Miyawaki, Brain Science Institute, Wako City, Japan), split at nucleotide 465 by PCR (Shyu et al., 2006), were fused to full-length murine SMN, SMN $\Delta \mathrm{T}, \mathrm{SMN}^{\mathrm{E} 134 \mathrm{~K}}, \mathrm{SMN}^{\mathrm{G} 279 \mathrm{~V}}$, human Gemin2, murine Unrip, human SmD1, and human $\mathrm{HuD}$ cDNAs. A point mutation (A206K) was introduced to generate a monomeric form of VFP as described previously (Zacharias et al., 2002). Neuro2a cells were cultured in DMEM (Invitrogen) supplemented with 10\% FBS (Sigma) and 1\% PenStrep (Invitrogen). Cells were transfected with TurboFect (Fermentas) according to the manufacturer's instructions. DNA for each BiFC plasmid, the pECFP-C1 plasmid (Clontech), coding for the cyan fluorescent protein, and the pcDNA3 carrier DNA, were used for transfection in a ratio of 1:1:1:5. Cells were fixed with 4\% paraformaldehyde in PBS $12 \mathrm{~h}$ after transfection and three-dimensional (3D) stacks ( $10-20$ sections, 0.6 $\mu \mathrm{m}$ thickness) were acquired using a wide-field fluorescence microscope (TE2000, Nikon).

Data analysis. Fluorescence $Z$-stacks were deconvolved (Autodeblur, Media Cybernetics) and analyzed using the Imaris software (Bitplane). For colocalization and fluorescence intensity analysis, $70-80 \mu \mathrm{m}$ of the axon starting from the cell body were analyzed. Background fluorescence was subtracted in all channels, and fluorescence intensities were thresholded to discriminate between signal and noise. For colocalization analysis, stringent thresholds and parameters were used to identify colocalized signal following the method developed by Costes et al. (2004), and implemented in the Imaris image analysis suite. For particle counting, granules with a diameter between 0.2 and $0.4 \mu \mathrm{m}$ and fluorescence intensity significantly higher than background were considered. For BiFC experiments, $>100$ cells per condition from 3 independent experiments were quantified. Fluorescence from ECFP was used to identify transfected cells and to normalize the VFP signal for transfection efficiency. Since the intensity of the BiFC signal depends on the relative orientation of the fusion proteins within the complex and cannot be directly compared among different BiFC protein pairs (e.g., SMNGemin2 vs SMN-SMN), the number of BiFC-positive cells was quantified. Cells were considered BiFC-positive if the VFP fluorescence was at least 1.5-fold higher than autofluorescence from cells transfected with ECFP alone. For comparing the BiFC signal of different SMN mutants, 


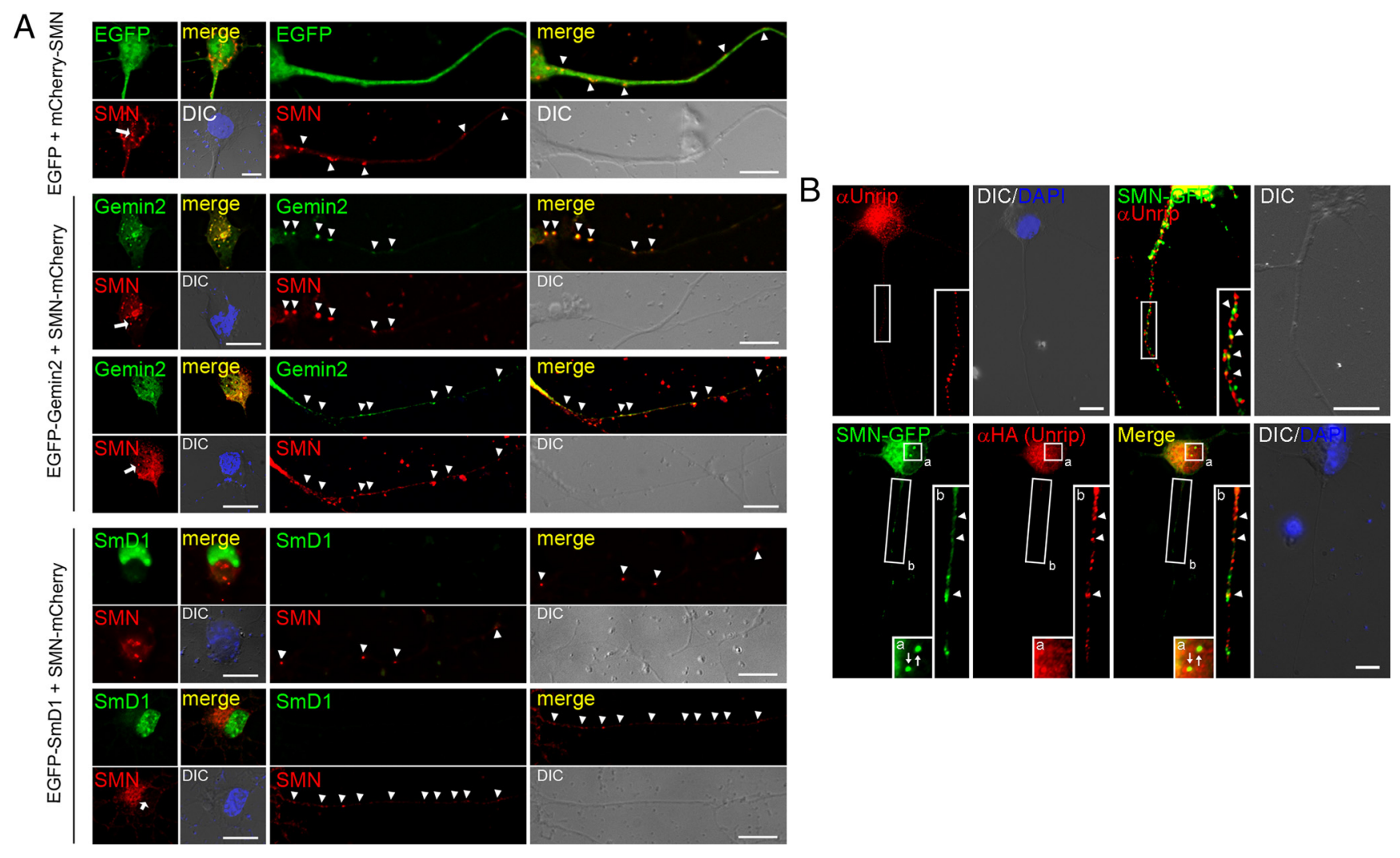

Figure 1. SMN colocalizes with Gemin2 and Unrip but not SmD1 in motor neuron axons. A, Cotransfection of an SMN-mCherry fusion construct with EGFP (top), EGFP-Gemin2 (middle), and EGFP-SmD1 (bottom) in primary motor neurons. SMN localizes to nuclear gems (left two panels, arrows), and granules in the cytoplasm and axon (right two panels, arrowheads). Axonal SMN-positive granules (arrowheads) contain Gemin2 but not SmD1, whose localization is restricted to the nuclear compartment, with few cytoplasmic granules colocalizing with SMN. $\boldsymbol{B}$, Endogenous (top) and HA-tagged (bottom) Unrip is present in motor neuron axons and partially colocalizes with SMN-GFP in axonal granules (arrowheads) but not in nuclear gems (arrows). Insets are enlarged images of boxed sections. Scale bars, $10 \mu \mathrm{m}$.

mean VFP fluorescence intensity, normalized to the ECFP signal, was quantified.

Live cell imaging. Motor neurons were plated on poly-ornithine/ laminin-coated Delta T culture dishes (Bioptechs). Twenty-four hours after transfection, cells were starved in plain Neurobasal medium for 30 min and then stimulated for $15 \mathrm{~min}$ with $10 \mathrm{ng} / \mu \mathrm{l}$ BDNF or $100 \mu \mathrm{M}$ Br-cAMP (Calbiochem) in glia-conditioned low fluorescence-imaging medium (Hibernate E, BrainBits) supplemented with 2\% B27 and 2\% horse serum. Movies were acquired using a wide-field microscope (TE2000, Nikon) with a high-speed cooled CCD camera (Cascade 512b, Photometrics) or a confocal microscope (A1R, Nikon).

Fluorescence in situ hybridization. A digoxigenin (DIG)-labeled oligo $\mathrm{dT}$ probe (Biosearch Technologies) was used to detect poly(A)-positive mRNAs. Fluorescence in situ hybridization (FISH) was performed as described previously (Bassell et al., 1994, 1998) with some modifications. Briefly, fixed motor neurons were rinsed in PBS containing $5 \mathrm{~mm} \mathrm{MgCl}_{2}$ and equilibrated in 15\% formamide (Sigma), $1 \times$ SSC for 5 min before preincubation in hybridization buffer ( $10 \%$ dextran sulfate, $2 \times$ SSC, 4 $\mathrm{mg} / \mathrm{ml}$ BSA, $20 \mathrm{~mm}$ ribonucleoside vanadyl complex, and $10 \mathrm{~mm}$ sodium phosphate buffer, $\mathrm{pH} 7.0)$ at $37^{\circ} \mathrm{C}$ for $1.5 \mathrm{~h}$. Probes $(10 \mathrm{ng})$ were dried with $10 \mu \mathrm{g}$ each of $E$. coli tRNA and salmon sperm DNA and then resuspended in $15 \mu \mathrm{l}$ of $30 \%$ formamide, $2 \times$ SSC buffer. Probes were mixed with $15 \mu \mathrm{l}$ of hybridization buffer and incubated with the coverslips at $37^{\circ} \mathrm{C}$ overnight. After stringent washes with $15 \%$ formamide $/ 1 \times$ SSC, they were incubated with Cy3-labeled sheep anti-DIG antibody (Roche) at room temperature for $1 \mathrm{~h}$, followed by Cy3-labeled anti-sheep antibodies for $30 \mathrm{~min}$ (Jackson ImmunoResearch). The specificity of oligo dT probes was demonstrated using an oligo dA control probe as previously described (Bassell et al., 1994).

\section{Results}

\section{SMN colocalizes with Unrip and Gemin2 but not SmD1 in} motor neuron axons

SMN protein has been shown to localize to motor neuron axons where it may exert an important function for motor neuron maintenance in addition to its essential role in snRNP assembly (Burghes and Beattie, 2009; Rossoll and Bassell, 2009). To address this hypothesis, we first investigated the axonal colocalization of SMN with components of the classical SMN complex in primary mouse motor neurons using fluorescent reporters. SMN fused to the red fluorescent protein mCherry was coexpressed with EGFP alone, or with EGFP fused to Gemin2 or SmD1 (Fig. $1 A$ ). SMN strongly colocalized with Gemin2 in nuclear gems and in granules in the cell body. Additionally, as we had previously described using quantitative immunofluorescence (Zhang et al., 2006), substantial colocalization was observed in axonal particles. To find out whether these granules also contain snRNP core components, we investigated the colocalization of SMN with SmD1. GFP-tagged SmD1 was localized mainly to nuclei and cell bodies, where it colocalized with SMN. However, SmD1 was absent from axonal SMN-positive granules (Fig. $1 A$ ). To further investigate our hypothesis, we studied SMN colocalization with the cytoplasmic SMN complex component Unrip. Unrip was not associated with SMN in nuclear gems, confirming what has been described in HeLa cells (Grimmler et al., 2005). We were able to show that endogenous Unrip protein localizes to the axons of primary motor neurons and that both endogenous and HA- 
A

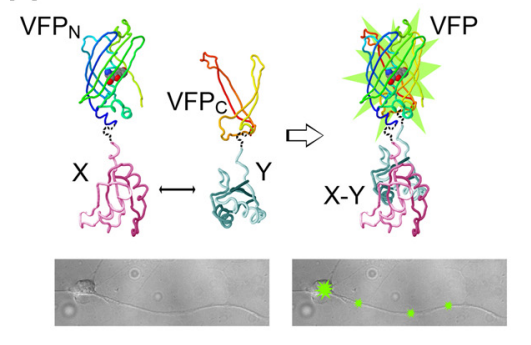

$\mathrm{C}$
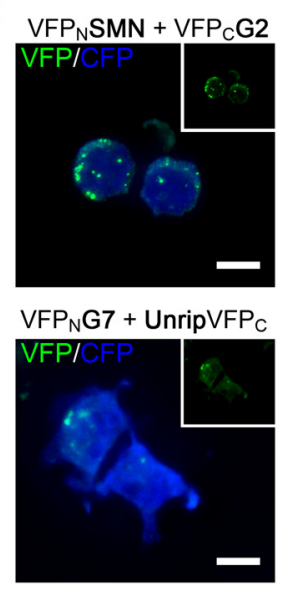

B

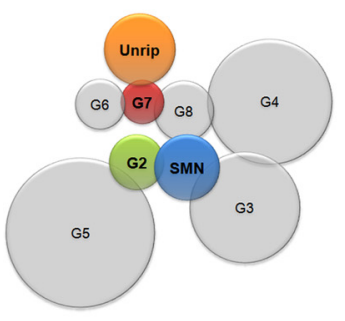

$\mathrm{D}$
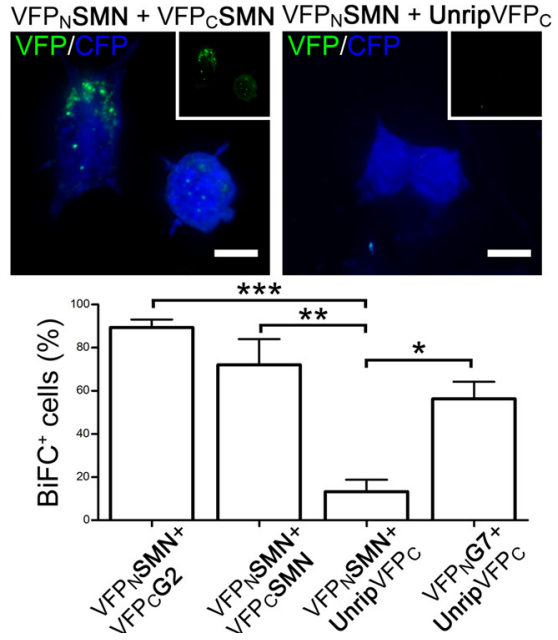

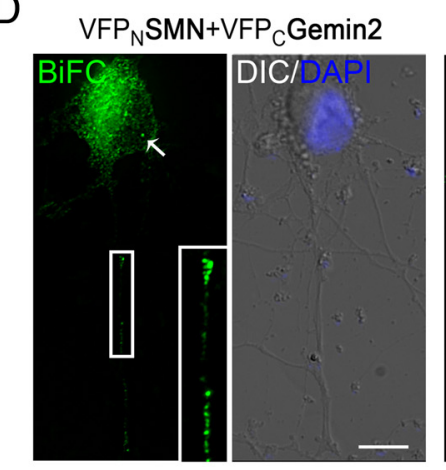

VFP $\mathrm{N}_{\mathrm{N}} \mathrm{SMN}+\mathrm{VFP} \mathrm{C}_{\mathrm{C}} \mathrm{SmD1}$

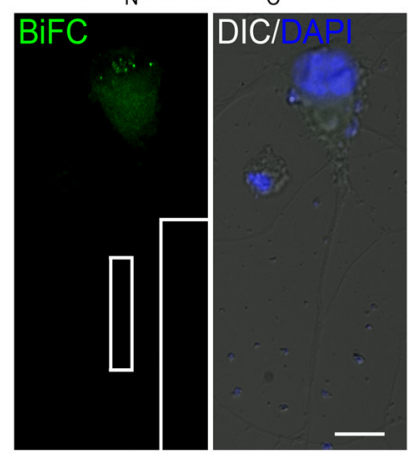

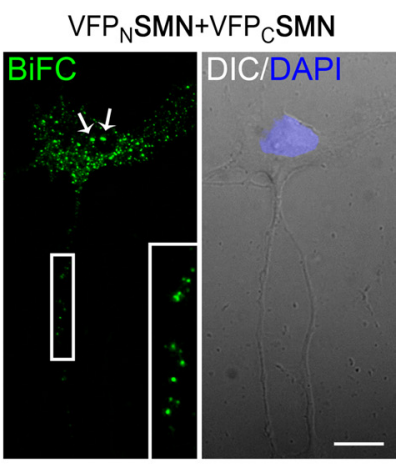

$\mathrm{E}$
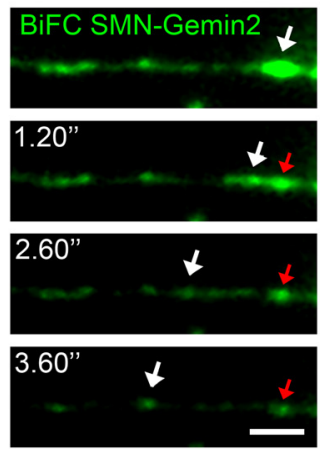

Figure 2. BiFC analysis of the SMN complex. A, Schematic representation of BiFC. Two halves of VFP are tethered together by the interaction of their fusion partners, allowing the fragments to complement and reconstitute the functional fluorophore. B, BiFC was used to study SMN interactions within the classical SMN complex, as described by 0tter et al. (2007). C, Neuro2a cells were cotransfected for $12 \mathrm{~h}$ with the BiFC pairs SMN-Gemin2, SMN-SMN, SMN-Unrip, and Gemin7-Unrip, and VFP mean fluorescence intensity was measured for each individual cell. Values $>1.5$-fold the background were considered positive (BiFC ${ }^{+}$; one-way ANOVA and Tukey's post hoc test, $n=168,150,155,198$ for SMN-G2, SMN-SMN, SMN-Unrip, and Unrip-G7, respectively; ${ }^{*} p<0.05$, ${ }^{* *} p<$ $\left.0.01,{ }^{* * *} p<0.001\right)$. CFP was used to identify transfected cells for the analysis. Insets show the VFP signal alone. D, BiFC was used in primary motor neurons to visualize the cellular localization of interactions. SMN-Gemin2 and SMN-SMN pairs show BiFC signal in both nuclear gems (arrows) and axonal granules (insets). SMN-SmD1 BiFC-positive granules are restricted to cell body and nucleus. $\boldsymbol{E}$, Live cell imaging of an SMN-Gemin2 BiFC granule in the axon of primary cultured motor neuron. The granule (arrows) moved for $8.66 \mu \mathrm{m}$ at an average speed of $3.09 \mu \mathrm{m} / \mathrm{s}$ (starting position is indicated by the red arrows). The apparent reduction in the size of the granules over time is due to VFP photobleaching during the movie acquisition. Scale bars: $\boldsymbol{C}, \boldsymbol{E}, 5 \mu \mathrm{m} ; \boldsymbol{D}, 10 \mu \mathrm{m}$.

tagged Unrip partially colocalized with SMN-GFP in axonal granules (Fig. $1 B$ ).

Together, our data show that SMN axonal granules are different in nature from spliceosomal snRNPs, although they may share some components of the classical SMN complex (i.e., Gemin proteins).

\section{BiFC shows $\mathrm{SMN}$ association with interacting proteins in the SMN complex}

To quantify SMN protein-protein interaction within specific subcellular compartments, we have used the BiFC technique (Kerppola, 2009). BiFC allowed us to image protein-protein interactions at high spatial resolution in defined cell volumes, using deconvolution, $3 \mathrm{D}$ reconstruction and digital image analysis. In this assay, the two nonfluorescent halves of VFP, fused to two putative interacting proteins, can complement and reconstitute the functional fluorophore if the two fusion partners are brought into close proximity (Fig. 2A). To test whether this method was suitable to study SMN associations within a single particle, we have analyzed SMN interaction with different components of the classical SMN complex (Fig. 2B) (Otter et al., 2007). Neuro2a neuroblastoma cells were transfected with constructs encoding for the N-terminal VFP fragment $\left(\mathrm{VFP}_{\mathrm{N}}\right)$ fused to $\mathrm{SMN}$, and for the C-terminal VFP fragment $\left(\mathrm{VFP}_{\mathrm{C}}\right)$ fused to Gemin2, $\mathrm{SMN}$, or Unrip (Fig. 2C). To identify transfected cells in an unbiased manner, a plasmid encoding cyan fluorescent protein (CFP) was cotransfected and CFP-positive cells were selected for analysis. When SMN and Gemin2 were tested for their interaction, $89 \%$ of CFP-positive cells showed average BiFC fluorescence intensities that were at least 1.5-fold higher than mock transfected cells. These data are consistent with the known direct binding between SMN and Gemin2 (Liu et al., 1997). We also investigated SMN self-association, which appears essential for its function (Lorson et al., 1998), yet has never been visualized in cells. BiFC-positive SMN-SMN granules were evident in $72 \%$ of transfected cells. As expected, these SMN-SMN granules were localized both in the cytoplasm and in nuclear bodies resembling gems. On the other hand, when the SMN-Unrip BiFC pair was tested, only $13 \%$ of cells showed significant fluorescence levels, consistent with biochemical evidence that SMN association with Unrip in the multimeric complex is indirect (Fig. 2B) (Otter et al., 2007). To exclude artifacts due to protein fusion, we tested different orientation of the fusion proteins (N- or C-terminal to VFP) for both Unrip and SMN, but all variations yielded negative results (data not shown). Since the association of Unrip to the SMN-complex is mediated via interaction with Gemin7 (Otter et al., 2007), we tested for a possible Unrip-Gemin7 association, and we observed that $56 \%$ of cells showed a BiFC-positive interaction. As expected, only cytoplasmic Unrip-Gemin7 BiFC granules were observed. These results strongly suggest that the relative distance of SMN and Unrip within the SMN complex (Fig. $2 B$ ) was responsible for the low level of complementation observed. 
Since we have established BiFC as a method to map protein-protein interactions in multiprotein complexes, we then applied it in motor neurons to study the cellular distribution of SMNSMN dimers compared with Gemin2SMN and SmD1-SMN complexes. Interestingly, while SMN-Gemin2 and SMN-SMN BiFC granules were localized in nuclear gems, as well as in the cell bodies and axons, and SMN-SmD1 BiFCpositive granules were visible only in the nucleus and cytoplasm of the cell body but not in the axons (Fig. 2D). This also prompted us to employ the BiFC technique, for the first time, for live cell imaging to investigate the cotransport of SMN and Gemin 2 in individual particles along motor neuron projections. We observed SMN-Gemin2 BiFC fluorescent granules moving both retrogradely and anterogradely at an average speed of $2.6 \mu \mathrm{m} / \mathrm{s}$, which is consistent with the fast axonal transport of SMN (Fig. 2E; supplemental Movie S1, available at www.jneurosci.org as supplemental material) (Zhang et al., 2003; Fallini et al., 2010).

Our results confirm the existence of different SMN complexes in the cell body versus axons and establish BiFC as a valuable tool to characterize SMN interaction with RNA-binding proteins within individual particles.

\section{SMN interacts with the mRNA-binding protein $\mathrm{HuD}$}

Since we could show that SMN localizes to motor neuron axons and is cotransported with Gemin2, we decided to investigate whether it was able to interact with the mRNA-binding protein $\mathrm{HuD}$, due to its well established role in axonal mRNA posttranscriptional regulation (PerroneBizzozero and Bolognani, 2002). HuD and the other members of the ELAV protein family are expressed in postmitotic neurons in the CNS. However, HuD expression in motor neurons has never been studied. We could detect $\mathrm{HuD}$ protein in both embryonic and adult mouse spinal cord lysates by Western blot analysis (supplemental Fig. S1, available at www. jneurosci.org as supplemental material).

More importantly, we could also show that endogenous $\mathrm{HuD}$ is present in granules along the axons and growth cones of primary motor neurons by using both a monoclonal and a polyclonal antibody (Fig. 3A). Previous studies have implicated $\mathrm{HuD}$ in the regulation of axonal and dendritic mRNA transport in hippocampal neurons (Bolognani et al., 2004; Tiruchinapalli et al., 2008). Thus, we investigated HuD transport in motor neurons using an EGFP-HuD construct. By using time-lapse microscopy, we could show that $\mathrm{HuD}$ is actively transported in granules along the axon of motor neurons, as well as in axons

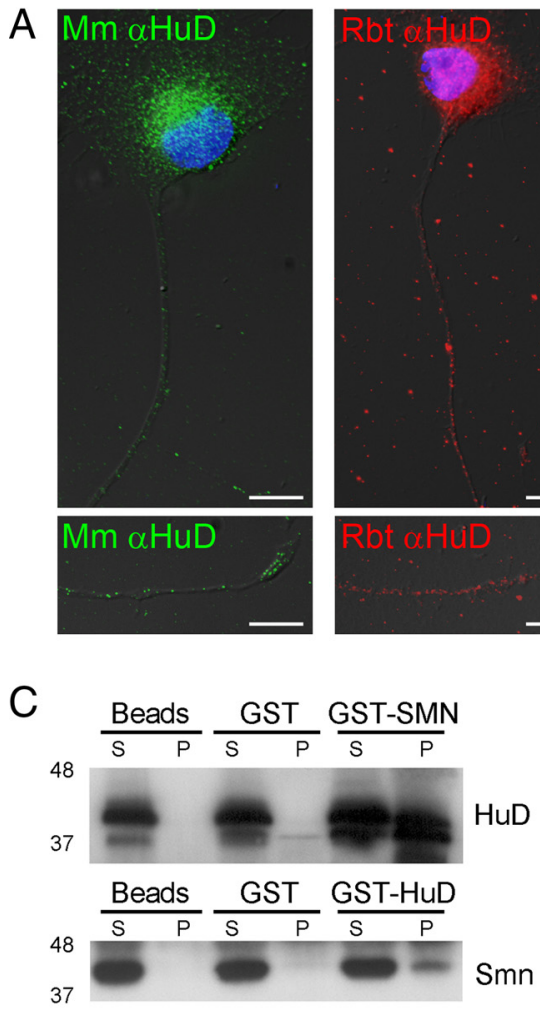

Rat E18 Brain

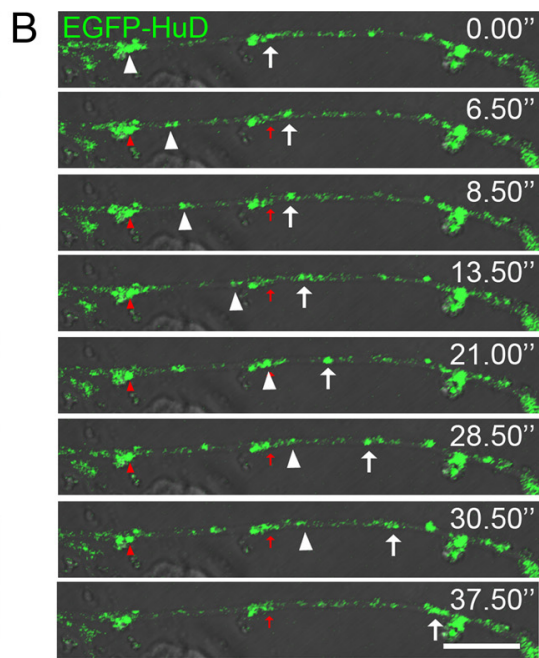

$\mathrm{D}$

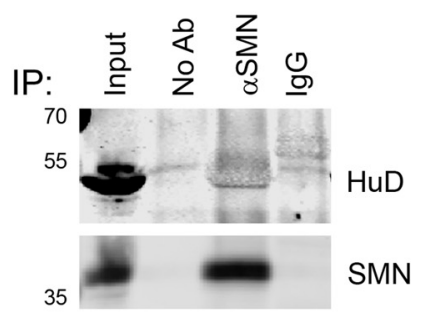

Rat E18 Spinal cord

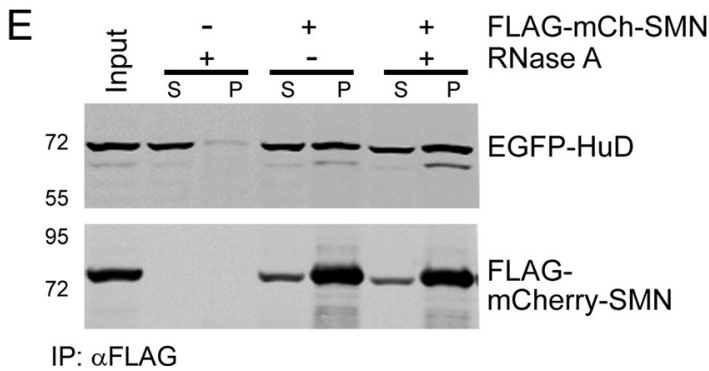

Figure 3. The mRNA-binding protein HuD localizes to motor neuron axons and is copurified with SMN. $\boldsymbol{A}$, Endogenous HuD was detected by immunostaining using a monoclonal mouse (Mm, left) or a polyclonal rabbit antibody (Rbt, right). HuD-positive granules were visible in the cell body and proximal axon (top), as well as in the growth cones (bottom). DAPI was used to stain nuclei (blue). $\boldsymbol{B}$, EGFP-HuD was expressed in primary motor neurons and active transport of granules was imaged by time lapse microscopy. The marked granules moved anterogradely toward the growth cone at an average speed of $0.75 \mu \mathrm{m} / \mathrm{s}$ (arrowheads) and $0.98 \mu \mathrm{m} / \mathrm{s}$ (arrows). Images of the fluorescent signals have been overlaid on DIC images in both A and B. Scale bars: $A, 10 \mu \mathrm{m}$; $\boldsymbol{B}, 5 \mu \mathrm{m}$. $\boldsymbol{C}$, Endogenous HuD (top) and SMN (bottom) were copurified from rat brain extracts using GST-fusions of SMN (top) and HuD (bottom). GST (lanes 3 and 4) or beads alone (lanes 5 and 6) were used as negative controls. D, Endogenous SMN protein was immunoprecipitated from E18 rat spinal cord lysates and the pellet was immunoblotted for HuD (top, lane 3) and SMN (bottom). Mouse IgG (lane 4) or no antibody (lane 2) were used as controls. Immunoprecipitation input is shown in lane 1. E, EGFP-HuD and FLAG-mCherry-SMN expressed in HEK293 cells were coprecipitated using an anti-FLAG antibody. A band corresponding to EGFPHuD was enriched in the immunoprecipitation pellet $(P)$ and present in the supernatant $(S)$ when FLAG-mCherry-SMN was coexpressed (lanes 4 -5). Pretreatment with $1 \mathrm{mg} / \mathrm{ml}$ RNase A for $1 \mathrm{~h}$ did not affect the interaction (lanes 7-8). Cells expressing EGFP-HuD alone (lanes 2-3) were used as a negative control. Immunoprecipitation input is shown (lane 1).

of chick forebrain neurons (Fig. 3B; supplemental Movie S2 and supplemental Fig. S2, available at www.jneurosci.org as supplemental material). Both antero- and retrograde movement of EGFP-HuD-positive granules was observed with a speed of $0.8 \pm 0.14 \mu \mathrm{m} / \mathrm{s}$.

To investigate whether SMN interacts with $\mathrm{HuD}$, we first performed pull-down assays. Rat brain extracts were incubated with GST-tagged $\mathrm{HuD}$ or SMN recombinant proteins (Fig. 3C). Endogenous SMN and $\mathrm{HuD}$ showed interactions with GST-tagged proteins, but not with the GST and beads only controls. To fur- 

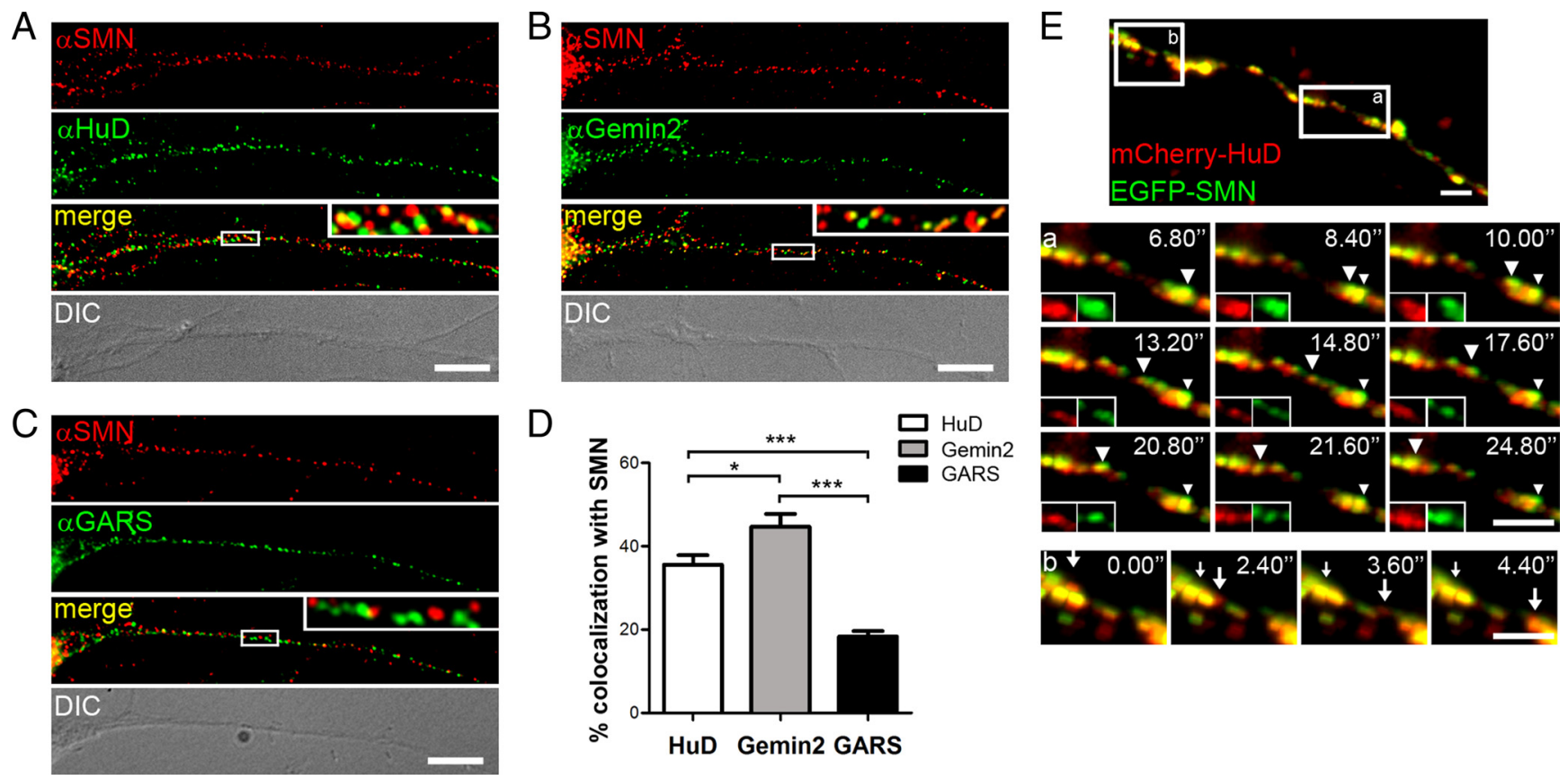

Figure 4. SMN and HuD colocalize and are cotransported in the same granule in motor neurons. $\boldsymbol{A}-\boldsymbol{C}$, Endogenous SMN and HuD $(\boldsymbol{A})$, Gemin2 $(\boldsymbol{B})$, and GARS $(\boldsymbol{C})$ proteins were detected by immunofluorescence in primary motor neurons. Strong colocalization was observed between SMN and HuD and SMN and Gemin2, but not between SMN and GARS (insets). D, Quantification of colocalization between each protein and SMN was performed. Bars represent mean and SEM (one-way ANOVA and Tukey's post hoc test, $n=30 ;{ }^{*} p<0.05,{ }^{* * *} p<0.001$ ). E, Dual fluorescenttagged SMN and HuD are cotransported in the same granule in the axon of motor neuron. The SMN-HuD colocalized granule shown in Ea (arrowheads) moved for $13.74 \mu \mathrm{m}$ with an average speed of $0.88 \mu \mathrm{m} / \mathrm{s}$. Single-channel magnifications of the granule are shown in the insets. A granule positive for mCherry-HuD alone is shown in $\boldsymbol{E} \boldsymbol{b}$ (arrows). Small arrowheads and arrows mark the initial position of the tracked granules. Scale bars: $\boldsymbol{A}-\boldsymbol{C}, 10 \mu \mathrm{m} ; \boldsymbol{E}, 5 \mu \mathrm{m}$.

ther confirm the interaction, endogenous SMN protein was immunoprecipitated from rat embryonic spinal cord lysates, and the immunoprecipitation was probed for the presence of $\mathrm{HuD}$ (Fig. 3D). Although weak, a band corresponding to $\mathrm{HuD}$ was visible in the SMN pellet, but not in the IgG or "no antibody" controls. To test whether the SMN-HuD association required the binding of $\mathrm{HuD}$ to RNA, protein lysates from HEK293 cells expressing EGFP-tagged HuD and FLAG-mCherry-SMN were incubated with RNase A for $1 \mathrm{~h}$ before purification (Fig. 3E). A band corresponding to EGFP-HuD was evident in the FLAG immunoprecipitation with or without RNase A pretreatment, suggesting that the SMN-HuD interaction does not depend on the presence of RNA in the complex. Together, these different assays demonstrate a biochemical association between $\mathrm{SMN}$ and $\mathrm{HuD}$.

\section{SMN and HuD colocalize in motor neuron axons}

Since we showed that $\mathrm{HuD}$ is localized in motor neuron axons and growth cones and that SMN and HuD are associated in spinal cord extracts, we investigated whether SMN and $\mathrm{HuD}$ also colocalize in axonal granules. Primary motor neurons were costained with SMN and $\mathrm{HuD}$ antibodies and a stringent statistical colocalization analysis (Costes et al., 2004) in deconvolved 3D reconstructions was performed. Interestingly, we observed that $35.6 \%$ of the HuD signal colocalized with SMN (Mander's coefficient 0.86 ) in the proximal axon of cultured motor neurons (Fig. 4A$D$ ), similar to the $44.7 \%$ colocalization observed with Gemin2 (Mander's coefficient 0.76 ), a well known SMN protein interactor. Conversely, the GARS, which shows a similar punctuate staining and has a similar abundance in the axon as $\mathrm{HuD}$, showed only $18 \%$ overlap with SMN granules. We have further confirmed the statistically nonrandom association between SMN and $\mathrm{HuD}$ by showing the colocalization of fluorescence-tagged SMN with endogenous and GFP-tagged $\mathrm{HuD}$ in motor neurons (supplemental Fig. S3, available at www.jneurosci.org as supplemental material) and hippocampal neurons (supplemental Fig. S4, available at www.jneurosci.org as supplemental material). We have shown previously that SMN-positive granules are also actively transported in different neuronal cell types (Zhang et al., 2003; Fallini et al., 2010). Therefore, we investigated whether $\mathrm{SMN}$ and $\mathrm{HuD}$ were cotransported in the same particle in motor neuron axons. For this purpose, cells were cotransfected with expression vectors for EGFP-SMN and mCherry-HuD. Cells were treated with $\mathrm{Br}$-cAMP or BDNF, which has previously been shown to stimulate microtubule-dependent localization of mRNP granules from the cell body into axons and growth cones (Zhang et al., 1999). Although neither BDNF nor Br-cAMP increased endogenous SMN localization in the axons, Br-cAMP significantly enhanced the number of $\mathrm{HuD}$-positive particles in the proximal axon of motor neurons (supplemental Fig. S5, available at www.jneurosci.org as supplemental material). Importantly, under these conditions we could show for the first time that fluorescent-tagged SMN is cotransported in the same particle with $\mathrm{HuD}$ in motor neuron axons (Fig. $4 C$; supplemental Movie S3, available at www.jneurosci.org as supplemental material). The majority of granules positive for both $\mathrm{SMN}$ and $\mathrm{HuD}$ did not move persistently along the axon but rather showed oscillatory movement, consistent with what was previously observed for SMN and Gemin2 (Zhang et al., 2003, 2006). Next, we used BiFC to investigate whether SMN and HuD are closely associated within the same granule or in two different but colocalized particles. BiFC constructs of SMN and HuD cDNAs fused to the N- and C-terminal fragments of VFP were cotransfected into primary motor neurons. Fluorescent BiFC signals showed that SMN and $\mathrm{HuD}$ are closely associated components of the same granule (Fig. 5). Importantly, BiFC-positive granules were localized mainly to the cell body and along the axon, while little or 

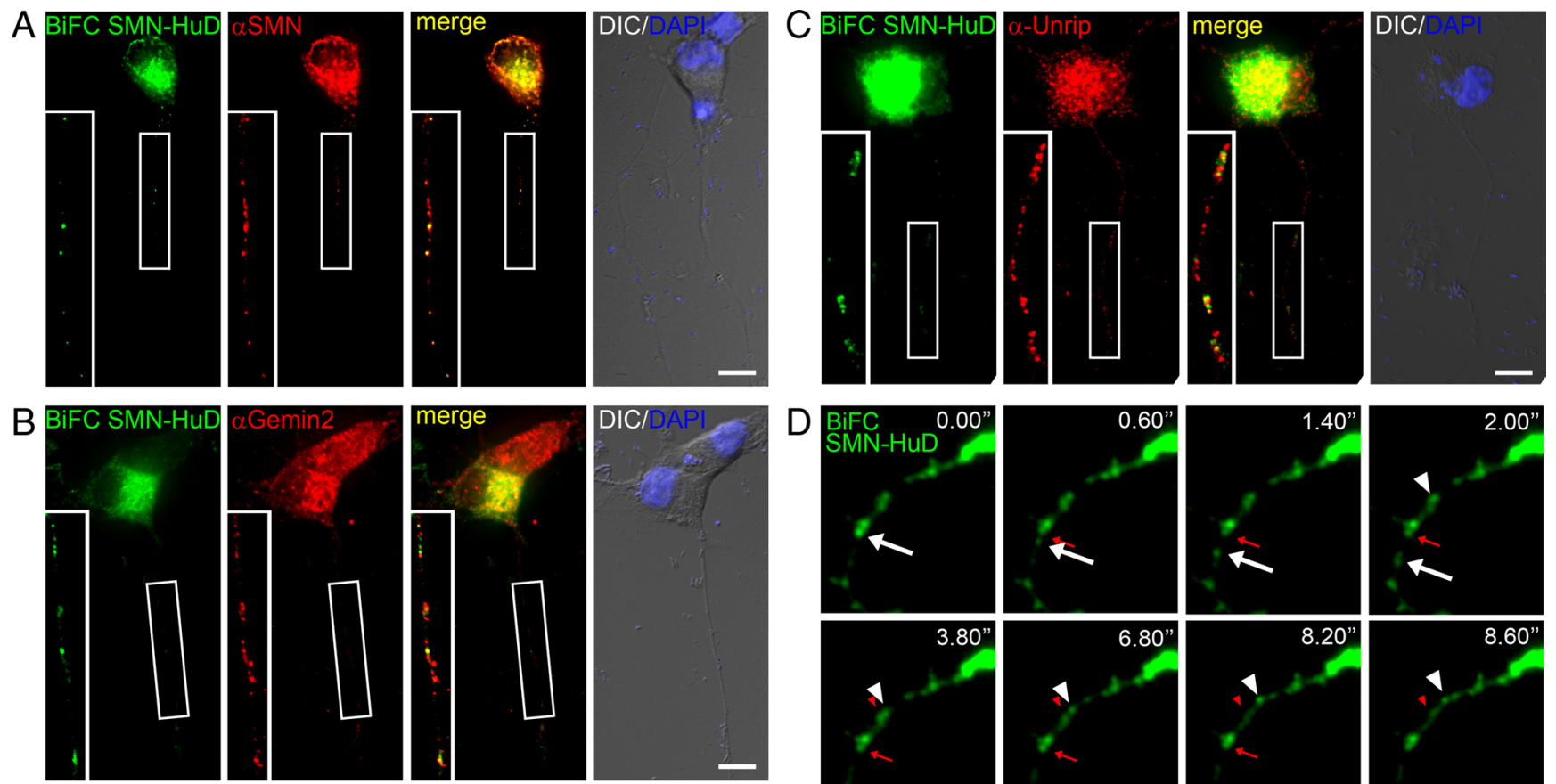
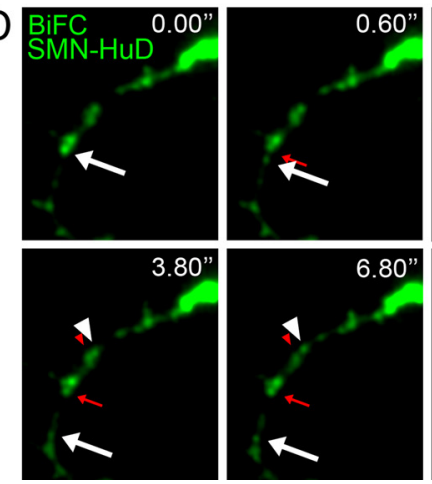
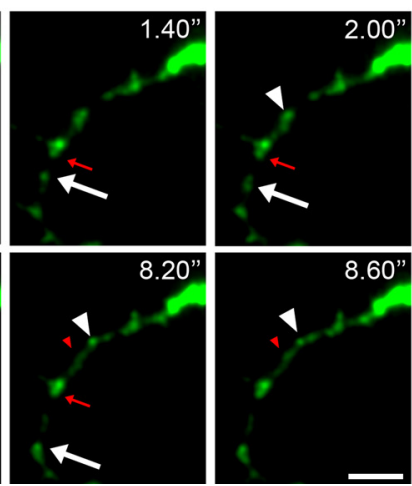

Figure 5. BiFC reveals SMN-HuD granules localized and actively transported along motor neuron axons. $A-C$, Primary motor neurons were transfected with SMN and HuD BiFC constructs and fixed $24 \mathrm{~h}$ posttransfection. BiFC granules (green) were stained using anti-SMN $(\boldsymbol{A})$, Gemin2 $(\boldsymbol{B})$, and Unrip $(\boldsymbol{C})$ antibodies (red). Positive granules were visible in the cell body and along the axon (insets). DAPI (blue) was used to identify nuclei. D, Time lapse microscopy was used to image SMN-HuD BiFC granules moving in motor neuron processes. Anterograde (arrows) and retrograde (arrowheads) trajectories were observed. Both granules moved at an average speed of $1 \mu \mathrm{m} / \mathrm{s}$. Red arrowheads and arrows mark the initial position of the tracked granules. Scale bars: $\boldsymbol{A}-\boldsymbol{C}, 10 \mu \mathrm{m} ; \boldsymbol{D}, 5 \mu \mathrm{m}$.

no signal was detected in the nuclear compartment. The SMN$\mathrm{HuD} \mathrm{BiFC}$ granules were also immunoreactive with antibody to SMN, Gemin2, and Unrip (Fig. 5A-C). We were able to demonstrate that $\mathrm{SMN}-\mathrm{HuD}$ BiFC granules move in both directions along motor neuron axons (Fig. 5D; supplemental Movie S4, available at www.jneurosci.org as supplemental material). These data demonstrate that SMN and $\mathrm{HuD}$ are components of multiprotein complexes that are actively transported along motor neuron axons.

\section{The SMN Tudor domain is necessary for interacting with $\mathrm{HuD}$}

To identify the SMN protein domain responsible for the interaction with $\mathrm{HuD}$, EGFP-tagged SMN constructs with deletions of the N-terminal 53 aa (SMN $\Delta$ N53), Tudor domain (SMN $\Delta \mathrm{T}$ ), or C-terminal exon-7 (SMN $\Delta 7)$ were tested by coimmunoprecipitation (Fig. $6 A, B$ ). $\mathrm{SMN} \Delta 7$, the major protein product of $S M N 2$ gene, as well as the SMN $\Delta$ N53 construct, which lacks the Gemin2-interacting domain (Liu et al., 1997), were still coprecipitated with FLAG-HuD. The deletion of SMN Tudor domain almost completely abolished SMN-HuD interaction (Fig. 6B). Moreover, we could show that the SMN Tudor domain is necessary and sufficient for the interaction with $\mathrm{HuD}$ (Fig. 6C). Interestingly, the Tudor domain is, together with the C-terminal YG box, an SMA mutation hotspot in the SMN1 gene (Rossoll and Bassell, 2009). To investigate whether SMA patient-derived missense mutations affect the ability of SMN to associate with $\mathrm{HuD}$, mutations in the Tudor domain (E134K) (Bühler et al., 1999) and YG box (G279V) (Hahnen et al., 1997) were introduced into the SMN sequence. We used the BiFC technique to quantitatively analyze protein-protein interactions in 3D-reconstructed cell volumes. We observed a significant reduction (35\%) in BiFC relative fluorescence intensity when the Tudor domain was de- leted compared with full-length SMN (Fig. 6D), confirming the biochemistry data shown earlier. Importantly, the E134K point mutation in the Tudor domain also significantly impaired SMN$\mathrm{HuD}$ association ( $80 \%$ in respect to SMN FL), while the G279V substitution did not have any effect ( $101 \%$ vs SMN FL). The same was observed when BiFC constructs were transfected in motor neurons (supplemental Fig. S6, available at www.jneurosci.org as supplemental material). Since SMN dimerization is supposed to be a prerequisite for SMN function, we investigated the possibility that the inability of the SMN mutant to interact with $\mathrm{HuD}$ was due to its failure to self-associate (Fig. $6 E$ ). While the mutation in the YG box, a domain known to be essential for SMN dimerization, significantly reduced the BiFC fluorescence, the E134K mutation had no effect. We also tested the effect of the mutations on the axonal localization of SMN. Motor neurons were transfected with EGFP-tagged SMN constructs, and the axonal fluorescence intensity was evaluated (Fig. 6F). We observed that the Tudor domain mutant had a similar axonal distribution as wild-type $\mathrm{SMN}$, while the $\mathrm{SMN}^{\mathrm{G} 279 \mathrm{~V}}$ localization to the axons was significantly reduced. Noteworthy, the total protein level for all SMN constructs was similar (data not show). Together, these results demonstrate that the Tudor domain is necessary and sufficient for SMN-HuD association and that an SMA patient-derived mutation in this domain significantly impairs this interaction. In addition, a disease-causing mutation in the YG box impairs dimerization and axonal localization of SMN. Together, these data suggest that disrupting the SMN-HuD interaction or axonal localization of SMN may contribute to SMA pathogenesis.

\section{HuD axonal localization is affected by SMN knockdown}

While we have demonstrated that SMN interacts in a Tudor domain-dependent manner with the mRNA-binding protein $\mathrm{HuD}$, and that the two proteins are cotransported within individ- 
A

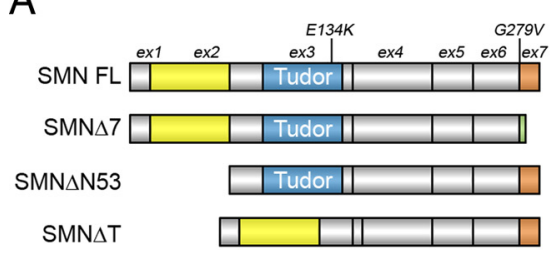

B
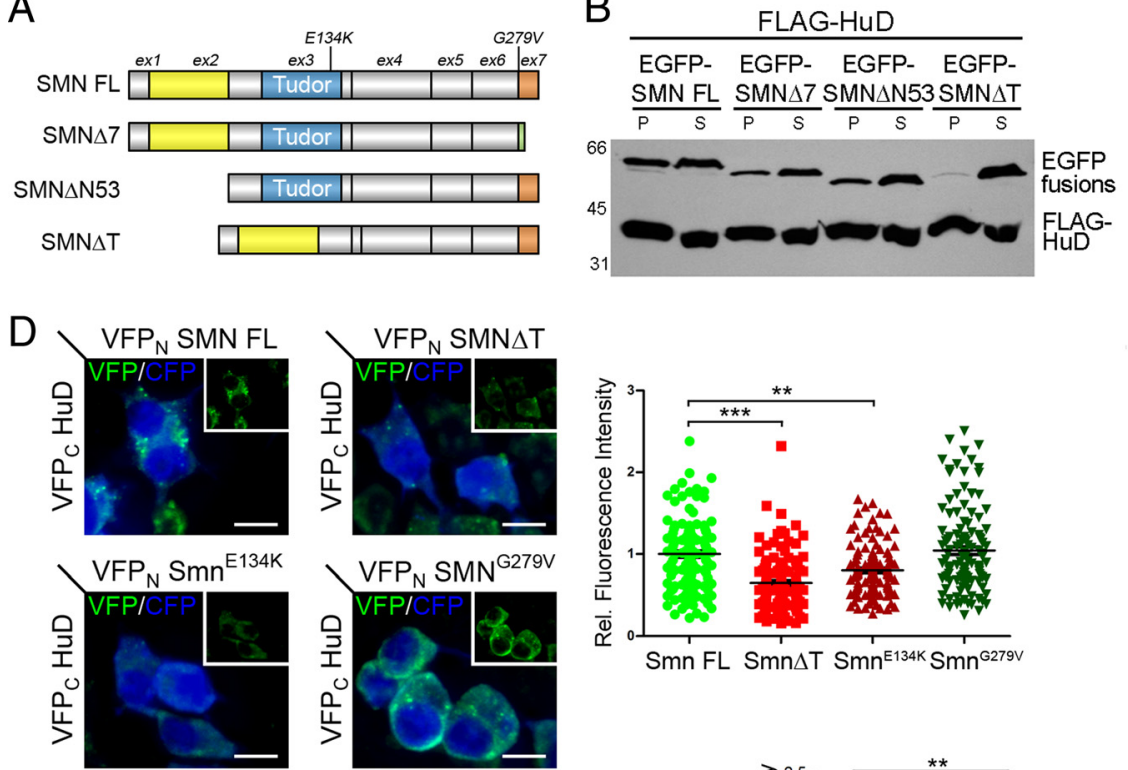

$\mathrm{E}$
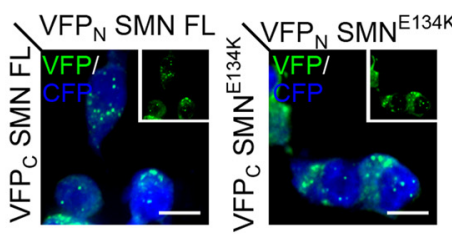
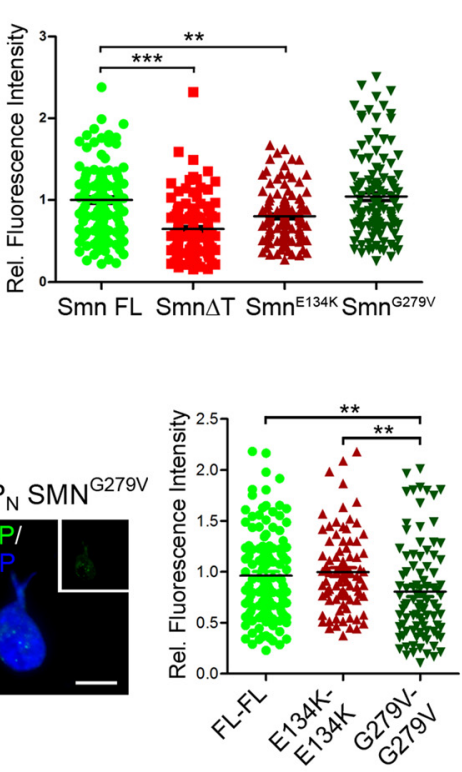

C

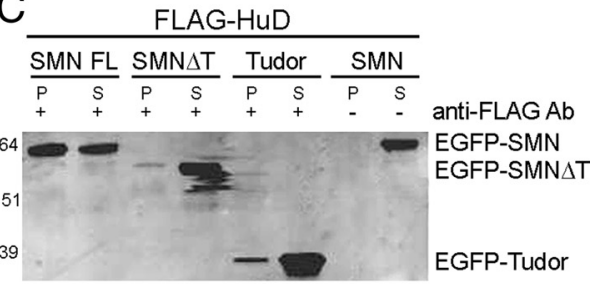

$\mathrm{F}$
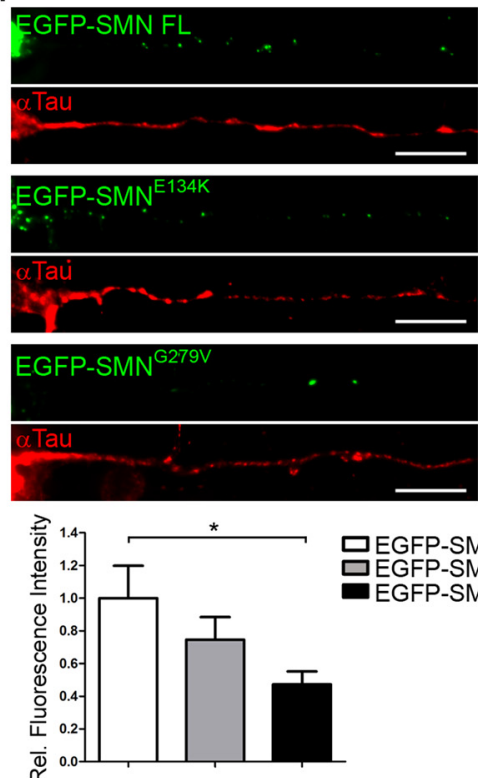

Figure 6. Deletion and mutation in the SMN Tudor domain specifically impair SMN-HuD interaction. $\boldsymbol{A}$, Schematic representation of SMN deletion constructs lacking exon 7 (SMN $\Delta 7$ ), the $N$ terminus (SMN $\Delta N 53$ ), or the Tudor domain (SMN $\Delta T$ ). The E134K (SMN ${ }^{\mathrm{E} 134 \mathrm{~K}}$ ) or the $\mathrm{G} 279 \mathrm{~V}\left(\mathrm{SMN}{ }^{\mathrm{G} 279 \mathrm{~V}}\right.$ ) mutations were introduced in the murine full-length SMN (SMN FL) sequence. $B$, $C$, Immunoprecipitation (IP) experiments with HEK293 cells transfected with EGFP- and FLAG-tagged SMN and HuD constructs. Anti-FLAG antibody was used to precipitate FLAG-tagged HuD. Monoclonal antibodies to GFP and FLAG were used for detection. SMN with the Tudor domain deletion (SMN $\triangle T$ ) failed to coprecipitate with HuD (B, lane 7), in contrast to SMN full-length and Nor C-terminal deletions. The Tudor domain alone, fused to EGFP, is sufficient to be copurified with FLAG-HuD (C, lane 5). P, IP pellet; S, IP supernatant. D, E, BiFC was used to investigate the effect of Tudor domain deletion or mutation on SMN-HuD interaction (D) and SMN self-association (E). Neuro2a cells were transfected with BiFC constructs and fixed after $12 \mathrm{~h}$. Murine full-length SMN (SMN $\mathrm{FL}), \mathrm{SMN} \Delta \mathrm{T}$, and Tudor domain (SMN ${ }^{\mathrm{E} 134 \mathrm{~K}}$ ) or YG-box mutants (SMN ${ }^{\mathrm{G} 279 \mathrm{~V}}$ ) were compared. Fluorescence intensity of the BiFC signal (green) was quantified and normalized to (FP protein expression (blue). Both deletion (SMN $\Delta \mathrm{T}$ ) and mutation (SMN ${ }^{\mathrm{E} 134 \mathrm{~K}}$ ) in the Tudor domain, but not in the YG-box (SMN ${ }^{\mathrm{G} 279 \mathrm{~V}}$ ), showed significantly reduced interactions with HuD (D, graph). In contrast, SMN ${ }^{\mathrm{G} 279 \mathrm{~V}}$ mutant showed impaired ability to self-associate compared with both SMN FL and the SMN ${ }^{\mathrm{E} 134 \mathrm{~K}}$ constructs (E, graph). Scatter plots represent the quantification of $80-120$ cells per condition from three independent experiments. Mean and SEM are shown (one-way ANOVA and Tukey's post hoc test, ${ }^{* *} p<0.01,{ }^{* * *} p<0.001$ ). $F$, Primary motor neurons were transfected with EGFP-fusions of wild-type or mutant SMN CDNAs (SMN FL, SMN ${ }^{E 134 K}$, and SMN ${ }^{\text {G279V }}$ respectively; green), and stained with tau antibody (red) to recognize the axons. EGFP fluorescence intensity was evaluated in the proximal axonal segment. A significant reduction was observed when the G279V mutation was present (one-way ANOVA and Tukey's post hoc test, $n=21,24$, and 27 for SMN $\mathrm{FL}, \mathrm{SMN}^{\mathrm{E} 134 \mathrm{~K}}$, and SMN ${ }^{\mathrm{G} 279 \mathrm{~V}}$ respectively; $\left.{ }^{*} p<0.05\right)$. Scale bars: $\boldsymbol{D}-\boldsymbol{F}, 10 \mu \mathrm{m}$.

ual granules, we also sought to investigate the functional implications of this interaction. To address this question, we have silenced SMN expression in wild-type motor neurons using a vector-base shRNA strategy (Fallini et al., 2010). The shRNAmediated SMN knockdown was used in these experiments to investigate the acute response following reduction of SMN levels, rather than the chronic effects of its gene deletion in animal models. Primary cultured motor neurons were transfected with an shRNA construct targeting SMN or with a nonsilencing control and incubated for $5 \mathrm{~d}$. We have previously shown that under these conditions SMN levels are strongly reduced both in the cell body and axon (Fallini et al., 2010). At first, we investigated the effect of SMN knockdown on Gemin2 levels, which are known to depend on SMN expression. As expected, we observed a significant reduction of Gemin 2 immunofluorescence in both cellular compartments $(48 \%$ and $64 \%$ in axons and cell bodies, respectively), which confirmed that the knockdown was efficient enough to affect SMN protein partners (Fig. $7 A, B$ ). Additionally, motor neurons transfected with the SMN-specific shRNA con- struct showed a $36 \%$ reduction in the number of nuclear gems [ 1.55 and 1 gems/cell in shRNA Ctrl (control) and shRNA SMN, respectively], identified by Gemin2 staining (Fig. 7C).

We then tested whether SMN knockdown also affected $\mathrm{HuD}$ protein levels. Interestingly, we observed a selective reduction of $\mathrm{HuD}$ immunofluorescence in the axonal compartment, while the cell body was relatively spared (76\% and $94 \%$ in axons and cell bodies, respectively). Also, the number of Gemin2- and HuDpositive particles in SMN knockdown axons was reduced compared with controls (Fig. 7D), while the average fluorescence intensity per particle did not change. These data suggest that SMN deficiency specifically impairs HuD trafficking in motor neuron axons, possibly by interfering with the assembly in mRNPs and/or transport of $\mathrm{HuD}$-containing mRNP complexes.

Poly(A)-mRNA localization in motor neuron axons is impaired following SMN knockdown

To investigate whether SMN deficiency would lead to a general defect in the axonal trafficking of mRNAs, we performed quan- 
titative FISH experiments. Motor neurons were transfected with shRNA constructs targeting SMN mRNA as described above, and poly(A)-positive mRNAs were detected by using a DIG-labeled oligo dT probe (Fig. $8 A$ ). To control for specificity of the signal, an oligo dA probe was used (Fig. 8B) (Bassell et al., 1994). Interestingly, we observed a significant $57 \%$ reduction in the fluorescence intensity of the poly(A) signal in the axonal compartment (Fig. 8C,D), while the cell body was unaffected (92.9\% of controls). When we compared the number of $\operatorname{poly}(\mathrm{A})^{+}$ mRNA-containing particles, we also observed a significant, although less dramatic, $31 \%$ decrease, suggesting that both the number of mRNP granules and the number of mRNA molecules per granules were affected. These data suggest that reduced SMN levels lead to a general impairment of the mRNA transport machinery, influencing the localization and possibly the composition of mRNPs.

\section{Discussion}

In this study, we have addressed a putative role for SMN in the regulation of axonal mRNA in motor neurons by combining different cell imaging tools, such as BiFC, quantitative colocalization and time-lapse video microscopy. We show that SMN is cotransported with the mRNA-binding protein $\mathrm{HuD}$ in axonal granules, and that this interaction depends on the SMN Tudor domain. Furthermore, we show that a single SMA patient-derived mutation in this domain abrogates the interaction. Importantly, we demonstrate that SMN deficiency in primary motor neurons leads to a reduction of $\mathrm{HuD}$ levels and a dramatic impairment of poly(A)-mRNA localization in axons. Together our results suggest that SMN interactions with mRNA-binding proteins can facilitate the localization of poly(A) associated mRNP complexes in axons.

SMN has a well established role in snRNP assembly, and although generalized splicing defects in various tissues have been observed in an SMA animal model (Zhang et al., 2008), currently there is no explanation for the selective vulnerability of motor neurons to low levels of SMN. We and others have hypothesized that SMN has additional roles in mRNA posttranscriptional regulation, such as modulation of mRNA transport and/or local translation at the distal ends of motor neurons, mechanisms required for the maturation and maintenance of neuromuscular junctions (Sendtner, 2001; Briese et al., 2005; Monani, 2005; Burghes and Beattie, 2009; Rossoll and Bassell, 2009). Our approach to better understand SMN axonal function was to investigate the composition of SMN-positive granules in motor neuron axons. Here, we combined high-resolution cell imaging and quantitative colocalization analysis with BiFC to discriminate between components of single particles and closely associated but distinct granules. BiFC is a well established technique for visualizing and quantifying protein-protein interactions (Kerppola, 2008), such as receptor subunits (Vidi et al., 2008; Ramírez et al., 2009) or transcription factors (Hu et al., 2002; Yuan et al., 2009).
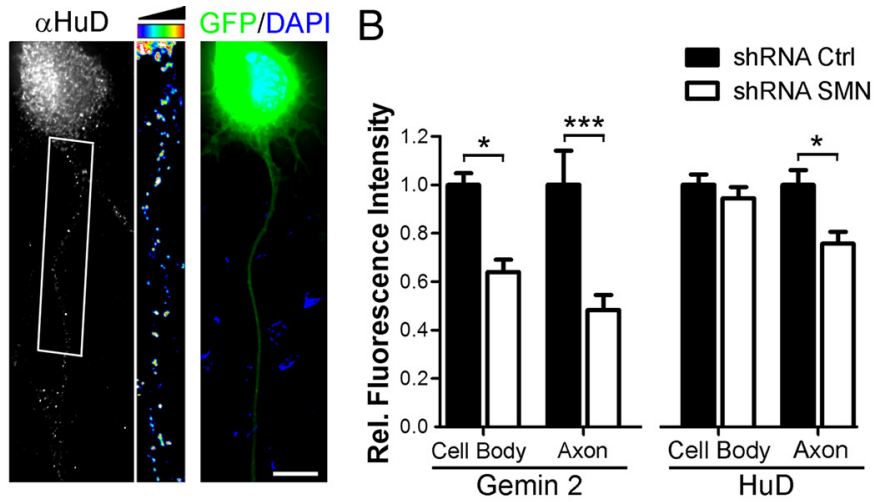

C
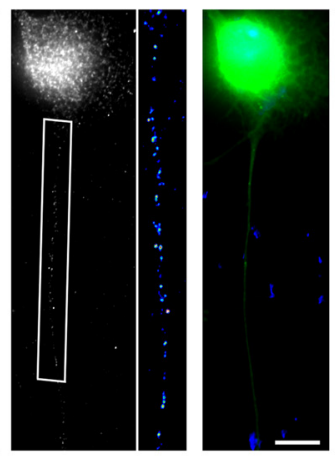

D

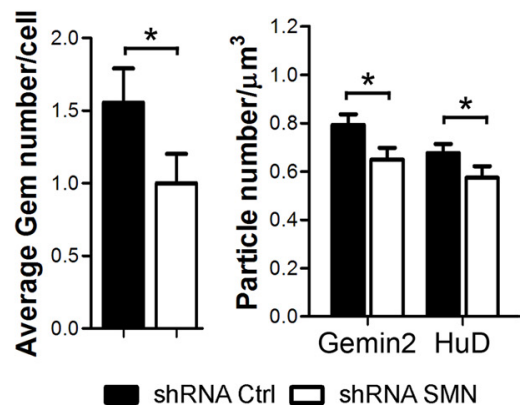

Figure 7. SMN deficiency impairs HuD axonal localization. $\boldsymbol{A}$, Primary motor neurons were transfected with an shRNA construct targeting SMN mRNA (bottom) or a nonsilencing control (top). Cells were fixed after $5 \mathrm{~d}$ and stained for Gemin2 (left) and HuD (right) proteins. GFP expression (green) was used to identify transfected motor neurons. Nuclei were stained with DAPI (blue). nucleus, were scored. Gem number decreased from $1.5 \pm 0.3$ in control cells to $1 \pm 0.7 \mathrm{gem} /$ cell in knockdown motor neurons (Student's $t$ test, $n=28,{ }^{*} p<0.05$ ). For all graphs, columns represent mean and SEM.

However, BiFC has been rarely used in primary neurons, and never to visualize the composition of single transport granules. Previously, we have quantified partial colocalization of endogenous SMN with Gemin2 and Gemin3 in axonal growth cones of hippocampal neurons (Zhang et al., 2006). Applying this novel approach in motor neurons, we now demonstrate that SMN dimerizes in axonal granules as well as in nuclear gems similarly to SMN-Gemin2 heterodimers, while the Sm core protein SmD1 is restricted to the cell body and nucleus. The relative distance of SMN and Unrip within the complex did not allow for BiFC detection, but we showed that Unrip is present in axonal granules, partially colocalizing with SMN and HuD. A model has been proposed in which Unrip provides a scaffold for the assembly of neuronal mRNPs containing MAP1B, Staufen-1, and nuclear export factors (Tretyakova et al., 2005). These observations, together with our new data, suggest that the function of Unrip and the SMN complex goes beyond snRNP assembly, and it may be involved in coupling mRNA splicing with nuclear export and microtubule-dependent mRNA trafficking.

Data from several laboratories have shown that SMN can associate with LSm proteins (di Penta et al., 2009) and several mRNA-binding proteins (Rossoll and Bassell, 2009), although until now, the only mRNA-binding protein that has been shown to colocalize with SMN in primary motor neurons is hnRNP-R (Rossoll et al., 2002). In this study we identified $\mathrm{HuD}$ as a new $\mathrm{SMN}$ interaction partner. $\mathrm{HuD}$ is a neuronal-specific mRNA- 


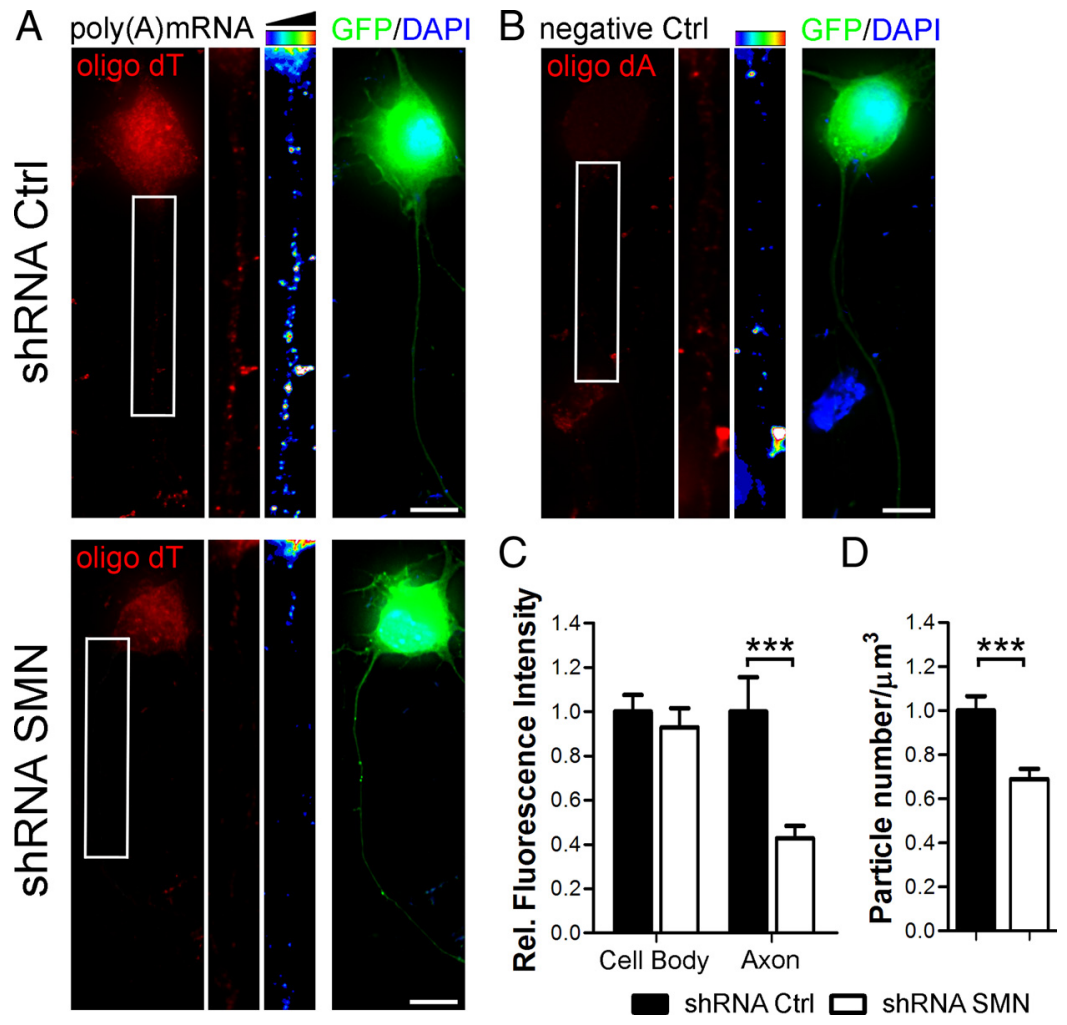

Figure 8. SMN knockdown impairs the localization of poly(A)-positive mRNA granules in motor neuron axons. $\boldsymbol{A}, \boldsymbol{B}$, Primary motor neurons were transfected with an shRNA construct targeting SMN mRNA (bottom) or a nonsilencing control (top). Cells were fixed after $5 \mathrm{~d}$ and processed for fluorescence in situ hybridization. Poly $(\mathrm{A})^{+}$mRNAs were detected using a DIG-labeled oligo dT probe (red) $(\boldsymbol{A})$. The specificity of the signal was controlled by using an oligo dA probe $(\boldsymbol{B})$. GFP expression (green) was used to identify transfected motor neurons. Nuclei were stained with DAPI (blue). Axons were straightened and pseudo-colored with a 16-color intensity map (insets). Scale bar, $10 \mu \mathrm{m}$. C, $\boldsymbol{D}$, Average fluorescence intensity $(\boldsymbol{C})$ and number $(\boldsymbol{D})$ of poly $(A)^{+} \mathrm{mRNA}$ containing granules were quantified in the proximal axonal fragment and cell body of shRNA SMN and control (Ctrl) cells from three independent experiments. Both parameters were significantly reduced in respect to controls by $58 \%$ and $31 \%$, respectively (one-way ANOVA and Tukey's post hoc test, $n=31$ for shRNA (trl and $n=36$ shRNA SMN respectively, ${ }^{* * *} p<0.001$ ). Bars represent mean and SEM.

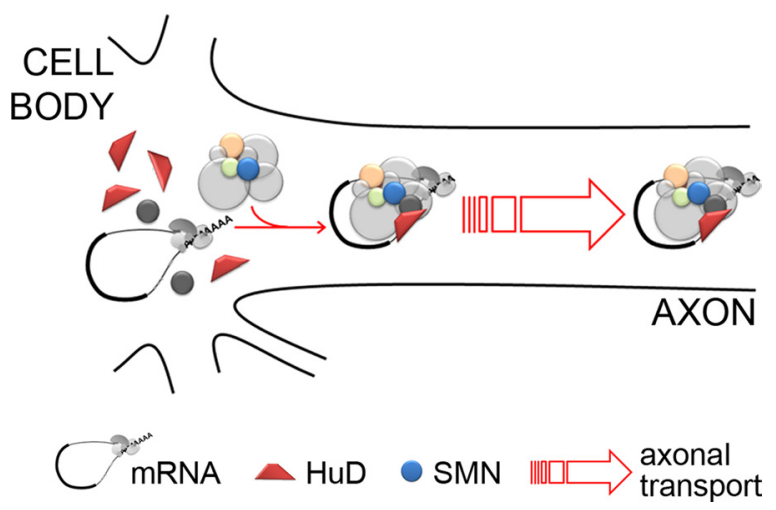

Figure 9. Proposed model for SMN function in motor neuron axons. SMN, either alone or associated with components of the SMN complex, facilitates the association of HuD and possibly other mRNA-binding proteins with target mRNAs and the trafficking of associated poly $(A)$ mRNAs from the cell body along the motor neuron axon.

binding protein that binds to AU-rich elements in the $3^{\prime} \mathrm{UTR}$ of target mRNAs affecting their stability, transport, and translation (Deschênes-Furry et al., 2005; Pascale et al., 2008). Gene deletion of elav, the $\mathrm{HuD}$ fly ortholog, leads to embryonic lethality due to defects in nervous system development (Robinow et al., 1988). In vertebrates, the ELAV family consists of four members, three of which, $\mathrm{HuB}, \mathrm{HuC}$, and $\mathrm{HuD}$, are selectively expressed in neurons, and the fourth, HuR, is ubiquitous (Good, 1995). $\mathrm{HuD}$ knock-out in mice leads to specific motor defects (Akamatsu et al., 2005), confirming the importance of mRNA regulation in the highly specialized motor neurons. $\mathrm{HuD}$ targets include $\beta$-actin mRNA and the microtubule associated protein tau mRNA, whose axonal localization is regulated by $\mathrm{HuD}$ (Aronov et al., 2002; Atlas et al., 2004). An extensive RIPChip analysis of $\mathrm{HuD}$ targets suggests a role for $\mathrm{HuD}$ in the regulation of actin dynamics (Bolognani et al., 2010). This is of particular importance, since a misregulation of actin cytoskeleton dynamics has been linked to SMA motor neuron defects (Oprea et al., 2008; Bowerman et al., 2009). One of the most studied HuD targets encodes the growth-associated protein 43 (GAP43) (Chung et al., 1997), which plays an important part in axon outgrowth and guidance, and in the regulation of actin filaments (Denny, 2006). The stability of GAP43 mRNA is under direct control of $\mathrm{HuD}$, and they colocalize in growth cones of PC12 cells (Mobarak et al., 2000; Smith et al., 2004). Interestingly, SMN knockdown disrupts GAP43 localization at the growth cones of neuronal cells (Bowerman et al., 2007). HuD also regulates mRNA stability and translation of the neuronal splicing factor Noval (Ratti et al., 2008). Mice lacking Noval exhibit defective muscle innervations and motor neuron firing (Ruggiu et al., 2009).

Based on our results, we speculate that SMN interacts with $\mathrm{HuD}$ and facilitates the association of $\mathrm{HuD}$ with mRNA and other proteins in mRNP complexes, similarly to SMN function in snRNP assembly. This hypothesis is supported by the finding that $\mathrm{SMN}$ interaction with $\mathrm{HuD}$ is mediated by the Tudor domain, which is responsible for SMN interaction with Sm and LSm proteins via dimethylarginine residues (Côté and Richard, 2005). The SMN Tudor domain also mediates interaction with the mRNA-binding protein KSRP (Tadesse et al., 2008), and both KSRP and HuD are substrates of CARM1 methyl transferase (Fujiwara et al., 2006). HuD activity is also modulated by $\mathrm{PKC} \alpha$-dependent phosphorylation, leading to enhanced binding, stability, and translation of its target mRNAs (Pascale et al., 2005; Ratti et al., 2008). It will be interesting to see whether $\mathrm{HuD}$ methylation and/or phosphorylation regulate SMN-HuD interaction.

A potential relevance of SMN-HuD association for SMA pathogenesis is implied by three observations. First, using BiFC as a tool to investigate SMN interactions in vivo, we show that a single nucleotide substitution in the SMN Tudor domain (E134K) impaired its binding to $\mathrm{HuD}$, and while a mutation in the YG-box had no effect on this interaction, it did impair SMN dimerization and axonal localization. The Tudor domain, together with the C-terminal YG-box, is a mutational hot spot in SMA (Rossoll and Bassell, 2009). Our data are consistent with previous reports that showed that this mutation in the Tudor 
domain affects SMN nuclear import and interaction with other proteins, such as Sm proteins (Selenko et al., 2001; Narayanan et al., 2004), and YG-box mutations affect SMN activity by inhibiting its self-association (Burnett et al., 2009). Moreover, these data suggest a possible model for how different mutations that appear to affect different aspects of SMN function eventually lead to the development of SMA. Second, we observed that SMN reduction caused a selective decrease of $\mathrm{HuD}$ protein levels in motor neuron axons. It has been previously shown that SMN deficiency in SMA tissues or cell lines causes a more general downregulation of most of its interaction partners (Jablonka et al., 2001; Wang and Dreyfuss, 2001; Helmken et al., 2003; Tadesse et al., 2008), although in these studies their specific cellular distribution was not analyzed. Upon SMN knockdown, we observed a general decrease of Gemin 2 levels in both the axons and cell bodies, strongly suggesting that the selective reduction of the mRNA-binding protein $\mathrm{HuD}$ in the axonal compartment, but not in the cell body, is not due to our experimental paradigm but it is rather a specific consequence of SMN depletion. Thirdly, we demonstrate that SMN is necessary for the axonal localization of poly(A) mRNA-containing granules, since upon SMN knockdown both the number and fluorescence intensity of $\operatorname{poly}(\mathrm{A})^{+}$-particles were dramatically reduced in motor neuron axons. As of now, only $\beta$-actin mRNA levels were shown reduced in SMA motor neurons (Rossoll et al., 2003). Our observations suggest a more general role of SMN, and possibly other components of the SMN complex, in facilitating the assembly of mRNA-binding proteins on their target transcripts in axonal granules, thus mediating the transport and local translation of these mRNPs (Fig. 9). Our results suggest that mutations or reduced levels of SMN might impair the axonal localization or the interactions of mRNA with mRNA-binding proteins such as $\mathrm{HuD}, \mathrm{KSRP}$, and hnRNP-R/Q, thus leading to a defective subcellular localization of transcripts that may be required for motor neuron maintenance.

In conclusion, our results argue for a role of SMN in the axon to affect mRNP assembly and/or localization that is different from its canonical function in snRNP assembly, providing an alternative model to explain axonal defects in SMA. Here we provide a technological approach to further study the interactions of SMN with mRNA-binding proteins using quantitative immunofluorescence and BiFC, which will contribute to a better understanding of SMN function and the reason of the selective motor neuron degeneration observed in SMA.

Note added in proof. At the time the current article was under revision, another study was published providing additional evidence for SMN-HuD association in a motor neuronal cell line (Hubers et al., 2011).

\section{References}

Akamatsu W, Fujihara H, Mitsuhashi T, Yano M, Shibata S, Hayakawa Y, Okano HJ, Sakakibara S, Takano H, Takano T, Takahashi T, Noda T, Okano H (2005) The RNA-binding protein HuD regulates neuronal cell identity and maturation. Proc Natl Acad Sci U S A 102:4625-4630.

Anthony K, Gallo JM (2010) Aberrant RNA processing events in neurological disorders. Brain Res 1338:67-77.

Aronov S, Aranda G, Behar L, Ginzburg I (2001) Axonal tau mRNA localization coincides with tau protein in living neuronal cells and depends on axonal targeting signal. J Neurosci 21:6577-6587.

Aronov S, Aranda G, Behar L, Ginzburg I (2002) Visualization of translated tau protein in the axons of neuronal P19 cells and characterization of tau RNP granules. J Cell Sci 115:3817-3827.

Atlas R, Behar L, Elliott E, Ginzburg I (2004) The insulin-like growth factor mRNA binding-protein IMP-1 and the Ras-regulatory protein G3BP associate with tau mRNA and HuD protein in differentiated P19 neuronal cells. J Neurochem 89:613-626.
Bassell GJ, Powers CM, Taneja KL, Singer RH (1994) Single mRNAs visualized by ultrastructural in situ hybridization are principally localized at actin filament intersections in fibroblasts. J Cell Biol 126:863-876.

Bassell GJ, Zhang H, Byrd AL, Femino AM, Singer RH, Taneja KL, Lifshitz LM, Herman IM, Kosik KS (1998) Sorting of beta actin mRNA and protein to neurites and growth cones in culture. J Neurosci 18:251-265.

Battle DJ, Kasim M, Yong J, Lotti F, Lau CK, Mouaikel J, Zhang Z, Han K, Wan L, Dreyfuss G (2006) The SMN complex: an assembly machine for RNPs. Cold Spring Harb Symp Quant Biol 71:313-320.

Bolognani F, Merhege MA, Twiss J, Perrone-Bizzozero NI (2004) Dendritic localization of the RNA-binding protein $\mathrm{HuD}$ in hippocampal neurons: association with polysomes and upregulation during contextual learning. Neurosci Lett 371:152-157.

Bolognani F, Contente-Cuomo T, Perrone-Bizzozero NI (2010) Novel recognition motifs and biological functions of the RNA-binding protein $\mathrm{HuD}$ revealed by genome-wide identification of its targets. Nucleic Acids Res 38:117-130.

Bowerman M, Shafey D, Kothary R (2007) Smn depletion alters profilin II expression and leads to upregulation of the RhoA/ROCK pathway and defects in neuronal integrity. J Mol Neurosci 32:120-131.

Bowerman M, Anderson CL, Beauvais A, Boyl PP, Witke W, Kothary R (2009) SMN, profilin IIa and plastin 3: a link between the deregulation of actin dynamics and SMA pathogenesis. Mol Cell Neurosci 42:66-74.

Briese M, Esmaeili B, Sattelle DB (2005) Is spinal muscular atrophy the result of defects in motor neuron processes? Bioessays 27:946-957.

Bühler D, Raker V, Lührmann R, Fischer U (1999) Essential role for the tudor domain of SMN in spliceosomal U snRNP assembly: implications for spinal muscular atrophy. Hum Mol Genet 8:2351-2357.

Burghes AH, Beattie CE (2009) Spinal muscular atrophy: why do low levels of survival motor neuron protein make motor neurons sick? Nat Rev Neurosci 10:597-609.

Burnett BG, Muñoz E, Tandon A, Kwon DY, Sumner CJ, Fischbeck KH (2009) Regulation of SMN protein stability. Mol Cell Biol 29:1107-1115.

Chari A, Paknia E, Fischer U (2009) The role of RNP biogenesis in spinal muscular atrophy. Curr Opin Cell Biol 21:387-393.

Chung S, Eckrich M, Perrone-Bizzozero N, Kohn DT, Furneaux H (1997) The Elav-like proteins bind to a conserved regulatory element in the 3'-untranslated region of GAP-43 mRNA. J Biol Chem 272:6593-6598.

Costes SV, Daelemans D, Cho EH, Dobbin Z, Pavlakis G, Lockett S (2004) Automatic and quantitative measurement of protein-protein colocalization in live cells. Biophys J 86:3993-4003.

Côté J, Richard S (2005) Tudor domains bind symmetrical dimethylated arginines. J Biol Chem 280:28476-28483.

Datta PK, Chytil A, Gorska AE, Moses HL (1998) Identification of STRAP, a novel WD domain protein in transforming growth factor-beta signaling. J Biol Chem 273:34671-34674.

Denny JB (2006) Molecular mechanisms, biological actions, and neuropharmacology of the growth-associated protein GAP-43. Curr Neuropharmacol 4:293-304.

Deschênes-Furry J, Angus LM, Belanger G, Mwanjewe J, Jasmin BJ (2005) Role of ELAV-like RNA-binding proteins $\mathrm{HuD}$ and HuR in the posttranscriptional regulation of acetylcholinesterase in neurons and skeletal muscle cells. Chem Biol Interact 157-158:43-49.

di Penta A, Mercaldo V, Florenzano F, Munck S, Ciotti MT, Zalfa F, Mercanti D, Molinari M, Bagni C, Achsel T (2009) Dendritic LSm1/CBP80mRNPs mark the early steps of transport commitment and translational control. J Cell Biol 184:423-435.

Fallini C, Bassell GJ, Rossoll W (2010) High-efficiency transfection of cultured primary motor neurons to study protein localization, trafficking, and function. Mol Neurodegener 5:17.

Fujiwara T, Mori Y, Chu DL, Koyama Y, Miyata S, Tanaka H, Yachi K, Kubo T, Yoshikawa H, Tohyama M (2006) CARM1 regulates proliferation of PC12 cells by methylating HuD. Mol Cell Biol 26:2273-2285.

Good PJ (1995) A conserved family of elav-like genes in vertebrates. Proc Natl Acad Sci U S A 92:4557-4561.

Grimmler M, Otter S, Peter C, Müller F, Chari A, Fischer U (2005) Unrip, a factor implicated in cap-independent translation, associates with the cytosolic SMN complex and influences its intracellular localization. Hum Mol Genet 14:3099-3111.

Hahnen E, Schönling J, Rudnik-Schöneborn S, Raschke H, Zerres K, Wirth B (1997) Missense mutations in exon 6 of the survival motor neuron gene 
in patients with spinal muscular atrophy (SMA). Hum Mol Genet 6:821-825.

Helmken C, Hofmann Y, Schoenen F, Oprea G, Raschke H, RudnikSchöneborn S, Zerres K, Wirth B (2003) Evidence for a modifying pathway in SMA discordant families: reduced SMN level decreases the amount of its interacting partners and Htra2-beta1. Hum Genet 114:11-21.

Holt CE, Bullock SL (2009) Subcellular mRNA localization in animal cells and why it matters. Science 326:1212-1216.

Hu CD, Chinenov Y, Kerppola TK (2002) Visualization of interactions among bZIP and Rel family proteins in living cells using bimolecular fluorescence complementation. Mol Cell 9:789-798.

Hubers L, Valderrama-Carvaja H, Laframboise J, Timbers J, Sanchez G, Côté $\mathrm{J}$ (2011) HuD interacts with survival motor neuron protein and can rescue spinal muscular atrophy-like neuronal defects. Hum Mol Genet 20: 553-579.

Jablonka S, Bandilla M, Wiese S, Bühler D, Wirth B, Sendtner M, Fischer U (2001) Co-regulation of survival of motor neuron (SMN) protein and its interactor SIP1 during development and in spinal muscular atrophy. Hum Mol Genet 10:497-505.

Kerppola TK (2008) Bimolecular fluorescence complementation: visualization of molecular interactions in living cells. Methods Cell Biol $85: 431-470$

Kerppola TK (2009) Visualization of molecular interactions using bimolecular fluorescence complementation analysis: characteristics of protein fragment complementation. Chem Soc Rev 38:2876-2886.

Kolb SJ, Battle DJ, Dreyfuss G (2007) Molecular functions of the SMN complex. J Child Neurol 22:990-994.

Lemmens R, Moore MJ, Al-Chalabi A, Brown RH Jr, Robberecht W (2010) RNA metabolism and the pathogenesis of motor neuron diseases. Trends Neurosci 33:249-258.

Liu Q, Fischer U, Wang F, Dreyfuss G (1997) The spinal muscular atrophy disease gene product, SMN, and its associated protein SIP1 are in a complex with spliceosomal snRNP proteins. Cell 90:1013-1021.

Lorson CL, Strasswimmer J, Yao JM, Baleja JD, Hahnen E, Wirth B, Le T, Burghes AH, Androphy EJ (1998) SMN oligomerization defect correlates with spinal muscular atrophy severity. Nat Genet 19:63-66.

Meister G, Eggert C, Fischer U (2002) SMN-mediated assembly of RNPs: a complex story. Trends Cell Biol 12:472-478.

Mobarak CD, Anderson KD, Morin M, Beckel-Mitchener A, Rogers SL, Furneaux H, King P, Perrone-Bizzozero NI (2000) The RNA-binding protein $\mathrm{HuD}$ is required for GAP-43 mRNA stability, GAP-43 gene expression, and PKC-dependent neurite outgrowth in PC12 cells. Mol Biol Cell 11:3191-3203.

Monani UR (2005) Spinal muscular atrophy: a deficiency in a ubiquitous protein; a motor neuron-specific disease. Neuron 48:885-896.

Narayanan U, Achsel T, Lührmann R, Matera AG (2004) Coupled in vitro import of $\mathrm{U}$ snRNPs and SMN, the spinal muscular atrophy protein. Mol Cell 16:223-234.

Oprea GE, Kröber S, McWhorter ML, Rossoll W, Müller S, Krawczak M, Bassell GJ, Beattie CE, Wirth B (2008) Plastin 3 is a protective modifier of autosomal recessive spinal muscular atrophy. Science 320:524-527.

Otter S, Grimmler M, Neuenkirchen N, Chari A, Sickmann A, Fischer U (2007) A comprehensive interaction map of the human survival of motor neuron (SMN) complex. J Biol Chem 282:5825-5833.

Pascale A, Amadio M, Scapagnini G, Lanni C, Racchi M, Provenzani A, Govoni S, Alkon DL, Quattrone A (2005) Neuronal ELAV proteins enhance mRNA stability by a PKCalpha-dependent pathway. Proc Natl Acad Sci U S A 102:12065-12070.

Pascale A, Amadio M, Quattrone A (2008) Defining a neuron: neuronal ELAV proteins. Cell Mol Life Sci 65:128-140.

Perrone-Bizzozero N, Bolognani F (2002) Role of HuD and other RNAbinding proteins in neural development and plasticity. J Neurosci Res 68:121-126.

Ramírez OA, Vidal RL, Tello JA, Vargas KJ, Kindler S, Härtel S, Couve A (2009) Dendritic assembly of heteromeric gamma-aminobutyric acid type B receptor subunits in hippocampal neurons. J Biol Chem 284:13077-13085.

Ratti A, Fallini C, Colombrita C, Pascale A, Laforenza U, Quattrone A, Silani V (2008) Post-transcriptional regulation of neuro-oncological ventral antigen 1 by the neuronal RNA-binding proteins ELAV. J Biol Chem 283:7531-7541.
Robinow S, Campos AR, Yao KM, White K (1988) The elav gene product of Drosophila, required in neurons, has three RNP consensus motifs. Science 242:1570-1572.

Rossoll W, Bassell GJ (2009) Spinal muscular atrophy and a model for survival of motor neuron protein function in axonal ribonucleoprotein complexes. Results Probl Cell Differ 48:289-326.

Rossoll W, Kröning AK, Ohndorf UM, Steegborn C, Jablonka S, Sendtner M (2002) Specific interaction of Smn, the spinal muscular atrophy determining gene product, with hnRNP-R and gry-rbp/hnRNP-Q: a role for Smn in RNA processing in motor axons? Hum Mol Genet 11:93-105.

Rossoll W, Jablonka S, Andreassi C, Kröning AK, Karle K, Monani UR, Sendtner M (2003) Smn, the spinal muscular atrophy-determining gene product, modulates axon growth and localization of beta-actin mRNA in growth cones of motoneurons. J Cell Biol 163:801-812.

Ruggiu M, Herbst R, Kim N, Jevsek M, Fak JJ, Mann MA, Fischbach G, Burden SJ, Darnell RB (2009) Rescuing Z+ agrin splicing in Nova null mice restores synapse formation and unmasks a physiologic defect in motor neuron firing. Proc Natl Acad Sci U S A 106:3513-3518.

Selenko P, Sprangers R, Stier G, Bühler D, Fischer U, Sattler M (2001) SMN tudor domain structure and its interaction with the Sm proteins. Nat Struct Biol 8:27-31.

Sendtner M (2001) Molecular mechanisms in spinal muscular atrophy: models and perspectives. Curr Opin Neurol 14:629-634.

Shaner NC, Campbell RE, Steinbach PA, Giepmans BN, Palmer AE, Tsien RY (2004) Improved monomeric red, orange and yellow fluorescent proteins derived from Discosoma sp. red fluorescent protein. Nat Biotechnol 22:1567-1572.

Shyu YJ, Liu H, Deng X, Hu CD (2006) Identification of new fluorescent protein fragments for bimolecular fluorescence complementation analysis under physiological conditions. Biotechniques 40:61-66.

Sleeman JE, Lamond AI (1999) Newly assembled snRNPs associate with coiled bodies before speckles, suggesting a nuclear snRNP maturation pathway. Curr Biol 9:1065-1074.

Smith CL, Afroz R, Bassell GJ, Furneaux HM, Perrone-Bizzozero NI, Burry RW (2004) GAP-43 mRNA in growth cones is associated with HuD and ribosomes. J Neurobiol 61:222-235.

Tadesse H, Deschênes-Furry J, Boisvenue S, Côté J (2008) KH-type splicing regulatory protein interacts with survival motor neuron protein and is misregulated in spinal muscular atrophy. Hum Mol Genet 17:506-524.

Tiruchinapalli DM, Ehlers MD, Keene JD (2008) Activity-dependent expression of RNA binding protein $\mathrm{HuD}$ and its association with mRNAs in neurons. RNA Biol 5:157-168.

Tretyakova I, Zolotukhin AS, Tan W, Bear J, Propst F, Ruthel G, Felber BK (2005) Nuclear export factor family protein participates in cytoplasmic mRNA trafficking. J Biol Chem 280:31981-31990.

Vidi PA, Chemel BR, Hu CD, Watts VJ (2008) Ligand-dependent oligomerization of dopamine $\mathrm{D}(2)$ and adenosine $\mathrm{A}(2 \mathrm{~A})$ receptors in living neuronal cells. Mol Pharmacol 74:544-551.

Wang J, Dreyfuss G (2001) A cell system with targeted disruption of the SMN gene: functional conservation of the SMN protein and dependence of Gemin2 on SMN. J Biol Chem 276:9599-9605.

Yuan Z, Gong S, Luo J, Zheng Z, Song B, Ma S, Guo J, Hu C, Thiel G, Vinson C, Hu CD, Wang Y, Li M (2009) Opposing roles for ATF2 and c-Fos in c-Jun-mediated neuronal apoptosis. Mol Cell Biol 29:2431-2442.

Zacharias DA, Violin JD, Newton AC, Tsien RY (2002) Partitioning of lipidmodified monomeric GFPs into membrane microdomains of live cells. Science 296:913-916.

Zhang H, Xing L, Rossoll W, Wichterle H, Singer RH, Bassell GJ (2006) Multiprotein complexes of the survival of motor neuron protein SMN with Gemins traffic to neuronal processes and growth cones of motor neurons. J Neurosci 26:8622-8632.

Zhang HL, Singer RH, Bassell GJ (1999) Neurotrophin regulation of betaactin mRNA and protein localization within growth cones. J Cell Biol 147:59-70.

Zhang HL, Pan F, Hong D, Shenoy SM, Singer RH, Bassell GJ (2003) Active transport of the survival motor neuron protein and the role of exon-7 in cytoplasmic localization. J Neurosci 23:6627-6637.

Zhang Z, Lotti F, Dittmar K, Younis I, Wan L, Kasim M, Dreyfuss G (2008) SMN deficiency causes tissue-specific perturbations in the repertoire of snRNAs and widespread defects in splicing. Cell 133:585-600. 